\title{
Micro-Explosion of Liquid Intermediates During the Fast Pyrolysis of Sucrose and Organosolv Lignin
}

\author{
Jorge Montoya ${ }^{1}$ Brennan Pecha ${ }^{2}$ Farid Chejne Janna*1 ${ }^{* 1}$ Manuel Garcia-Perez*2 \\ ${ }^{1}$ Facultad de Minas, Universidad Nacional de, Colombia. \\ ${ }^{2}$ Washington State University, Pullman, WA 99164, USA.
}

(Paper submitted to J. Analytical and Applied Pyrolysis)

\begin{abstract}
A new methodology has been proposed to describe of the dynamics of bubble formation during pyrolysis of Organosolv lignin and sucrose (surrogates for biomass) using fast speed visualization (125fps) with mathematical modeling. The model uses a population balance to predict overall rates of bubble birth and death, bubble bursting, and aerosol ejection. The experimental studies were performed on a uniquely modified CDS Analytical Pyroprobe 5000 to visualize the formation of bubbles within the liquid intermediate phase at heating rates close $100{ }^{\circ} \mathrm{C} / \mathrm{s}$. Experimentally, we observed that bubbles follow a log-normal distribution versus bubble size within the liquid intermediate phase for both materials. This distribution function changes over time due to increased viscosity from solidification reactions that generate char and the changes in the rate of bubble formation. Micro-explosion intensity was used to estimate aerosol ejection intensity. The model predicts aerosol ejection yields of $21.18 \% \mathrm{w} / \mathrm{w}$ from Organosolv lignin and $17.40 \% \mathrm{w} / \mathrm{w}$ from sucrose during pyrolysis with an average droplet size of $10 \mu \mathrm{m}$.
\end{abstract}

Keywords: Fast Pyrolysis, liquid Intermediate Phase, Bubbling, micro-explosion, aerosol formation. 
*Corresponding Authors:

Manuel Garcia-Perez

Farid Chejne

Associate Professor

Associate Professor

Department of Biological Systems Engineering

Energy Processes School

Washington State University

National University of

Colombia

Phone: 509-335-7758

Phone: + 5745255333

e-mail: mgarcia-perez@wsu.edu

e-mail: fchejne@una.edu.co 


\section{Introduction}

Biomass fast pyrolysis is a relatively simple process, but is very challenging to control; it is a fast reaction in which heat transfer, mass transfer, and chemical reactions all impact the final distribution of products to varying degrees [1,2]. Lignocellulosic biomass is made up of cellulose, hemicelluloses, lignin, extractives, and ash. Many studies have been done to understand biomass pyrolysis using lignocellulose pseudocomponents like cellulose or lignin. Experimental and theoretical evidence show that during neat cellulose and lignin depolymerization, a short-lived liquid phase is formed before compounds are released from the biomass particle. This liquid phase is composed of heavy depolymerization products [3-6] and is the source of high molecular weight compounds (anhydro-sugars with DP > 2, pyrolytic lignin) in bio-oil $[3,7,8]$.

In the liquid intermediate phase, volatile products of pyrolysis reactions (vapors and gases) form bubbles. These bubbles grow, coalesce, and collapse to release aerosols that are made up of whatever is in the liquid at that time $[3,8,9]$. When bubbles rise to the surface the external liquid-gas interface swells, increasing the internal pressure of the bubble (see Figure 1A). When the internal energy exceeds the surface's free energy, the bubble collapses and bursts (see Figure 1B) [8]. As the bubble bursts and releases gas, the liquid surface deforms and "jets" are created (see Figure 1C). The jets then collapse and release large aerosols $(0.1-1 \mathrm{~mm})$ [10-12].

\section{Figure 1.}

The dynamics of bubble formation and collapse have been extensively studied in evaporative processes, droplet combustion processes, and aeration in gas/liquid interfaces on water surfaces [12-14]. For example, bubbling in rapid boiling processes have received a lot of attention [15-18]. Bubble dynamics are affected by temperature, fluid type, and the micro-structure of the surface. 
Micro-emulsion droplet combustion is a relevant example of a technology where microexplosions are important. During combustion, aerosols may be released totally or partially, destroying the mother droplet $[19,20]$. Microexplosion of droplets suspended on a thermocouple is commonly studied using fast speed cameras (> $1000 \mathrm{fps}$ ) to visualize morphological changes as a function of temperature and time [2125]. Pyrolysis oil (also known as bio-oil) is known to undergo microexplosions during combustion [25]. Bio-oil microexplosion intensity depends strongly on droplet size, temperature, and heating rate [23]. Shuhn et al. [26] described the swelling, bubbling, aerosol ejection phenomena during micro-explosions of fast pyrolysis bio-oil blends with diesel. Teixeira et al. [19] found that the presence of high molecular weight compounds $(1000 \mathrm{Da})$ in the bio-oil is important for the formation of microbursts. Filtration of these compounds (probably pyrolytic lignin) reduces the frequency of micro-explosions by $50 \%$. The presence of solids such as char does not appear to alter the dynamics of bubble formation or the intensity of microbursts. The dynamics of bubble formation during pyrolysis has also been studied for polymers [8] and coals [12,27].

One metric to study aerosol formation is the intensity of ejection. Aerosol ejection intensity is defined as the average total number of aerosol droplets ejected per unit time [3,28-30]. Several studies report a direct relationship between the diameter of the gas bubbles within the liquid phase and the size of aerosol ejected. These relationships depend on the physical and chemical nature of the fluid and conditions (temperature and pressure) of bubbling. Many researchers have attempted to correlate the dynamic ejection aerosols with the characteristics of gas bubbles during the bursting [28,29,31]. However, given the complexity of the phenomenon, it is difficult to make a universal description of aerosol ejection. Recently, Zhang et al. [29] proposed correlations with dimensionless numbers to establish relationships between the number of aerosols ejected as a function of the physicochemical properties of the medium (liquid phase), and the diameter of the bubbles before bursting. Knowing the dynamics of bubble formation, the physico-chemical properties of the liquid intermediate and existing correlations to calculate aerosol ejection intensity [29] could enhance the predictive quality of models describing biomass pyrolysis. 
Inherently connected to the outcome of the bubbling and thermal ejection phenomena is the biomass particle size. Particle size affects the internal microstructure of biomass particles and plays a determinant role in heat and mass transfer processes during biomass fast pyrolysis [32, 33]. It is known that the bio-oil yield decreases as the particle diameter increases, although it does not follow a linear trend. A dramatic reduction in bio-oil and oligomeric yield occurs when the particle size increases from less than $0.1 \mathrm{~mm}$ to $1 \mathrm{~mm}$. [5, 34, 35]. The decrease in the lignin oligomer yield is mainly due to retention of these compounds inside the biomass particles as they are released by thermal ejection within the pores $[1,5,35,36]$. Two pyrolysis regimes were suggested based on particle size [5, 35]. The first regime is for very small particles (mostly fragments of cell walls) which release aerosols directly off the cell walls into the reactor. In the second regime, the thermally ejected oligomers are trapped inside the cell cavities leading to the formation of secondary char and bio-oil with a lower content of oligomers [5].

Based on a thorough literature review, the authors conclude found a lack of information regarding bubble formation in fast pyrolysis of lignocellulosic materials and its contribution to aerosol ejection. In this study we aim to investigate this phenomena for

Organosolv lignin and sucrose using experimental and modelling approaches. Organosolv lignin and sucrose act as surrogates for biomass components lignin and cellulose, respectively [1]. Our goal is to advance our understanding of the processes of birth, growth, coalescence and microexplosion of bubbles in the liquid intermediate phase of pyrolysis.

\section{Materials and Methods}

\subsection{Materials}

In this work Organosolv lignin (371,017 Aldrich, CAS 8068-03-9) and sucrose (BioXtra, -Sigma $\geq 99.5 \%$ ) were used. The proximate analysis of the Organosolv lignin was determined in a Mettler Toledo TGA / SDTA 851 with $20 \mathrm{mg}$ of sample in an open alumina capsule using the following heating method: $\mathrm{N}_{2}\left(25-107{ }^{\circ} \mathrm{C}\right.$ at $100{ }^{\circ} \mathrm{C} / \mathrm{min}$, hold $60 \mathrm{~min}, 107-950{ }^{\circ} \mathrm{C}$ at $45{ }^{\circ} \mathrm{C} / \mathrm{min}$, hold $\left.7 \mathrm{~min}, 950-600{ }^{\circ} \mathrm{C},-100{ }^{\circ} \mathrm{C} / \mathrm{min}\right) \mathrm{O}_{2}\left(600-750{ }^{\circ} \mathrm{C}\right.$ 
at $2.5^{\circ} \mathrm{C} / \mathrm{min}$, hold $60 \mathrm{~min}$ ). Elemental analysis of both the Organosolv lignin and the sucrose was performed on a Leco TruSpec the protocole described elsewhere [37]. The results are shown in Table 1.

\section{Table 1.}

\subsection{Pyroprobe-based fast pyrolysis visualization reactor}

The formation of the intermediate liquid phase and bubble dynamics, were visualized with a fast camera. The studied material was deposited on quartz disks supported on a modified CDS Pyroprobe 5000. The reactor consists of a Pyrex tube (No 9825), cut open at the end, screwed into a solid block of aluminum by connection $1 / 2$ NPT and two lateral connections $1 / 4$ NPT to hold a pressure sensor and a valve that regulates a continuous flow of nitrogen. The shape of the platinum filament was modified to facilitate installation of a quartz disk of $1 \mathrm{~cm}$ in diameter and $0.5 \mathrm{~mm}$ thick, on which rests the sample to be displayed. Originally the filament was $12.2 \mathrm{~cm}$ in length, 0.3556 mm thick and forming a coil of 15 turns. The new filament has the same length and thickness, but arranged in a plane (See Figure 2-A).

\section{Figure 2.}

The visualization of the samples was performed with a fast camera (Troubleshooter Fastec LE Imagin Fastec $125 \mathrm{fps}$ ); using two $25 \mathrm{~mm}$ extension tubes each connected in series with a Tokina $100 \mathrm{~mm}$ f 2.8 lens. The camera was positioned at an approximately $45^{\circ}$ angle to the main axis of the quartz disc with the sample (see Figure 2-B). An external source of white light (Solarc LB50) was coupled to improve the depth of field and focus on each video. The amount of sample used in each experiment is approximately $0.5 \mathrm{mg}$, positioned in the center of the quartz disc (see Figure 2B). Analytical grade nitrogen flowed continuously at a rate of $5 \mathrm{ml} / \mathrm{min}$ to prevent the fumes from obstructing the field of view of the camera.

\subsection{Temperature Calibration}


Calibration curves were obtained with the blank disc, and with $0.5 \mathrm{mg}$ of each sample on it. Each assay was performed in triplicate to ensure reproducibility. The Pyroprobe was programmed with heating rate of $800{ }^{\circ} \mathrm{C} / \mathrm{s}$, and a final temperature of $337^{\circ} \mathrm{C}$ such that the disc surface was $500{ }^{\circ} \mathrm{C}$. In another experiment, the thermocouple was placed in the sample pile but without touching the quartz surface to measure the sample heating rate at the middle of the sample. The measurements were performed with a $50 \mu \mathrm{m}$ thermocouple (Type K, Omega), which has a response time of $2.36 \mathrm{~ms}$ (determined experimentally). A data acquisition system makes a record of the temperature every 0.25 s. Figures 2C-2D shows the temperature evolution of the empty disc and the samples. The maximum heating rate achieved on the surface of the blank disc was 181 ${ }^{\circ} \mathrm{C} / \mathrm{s}$, and an average for sucrose and lignin on the order of $120{ }^{\circ} \mathrm{C} / \mathrm{s}$. Differences in heating rate and final temperature are due to the physicochemical properties of carbonaceous residues formed. This information was used to correlate the temperature of the sample and the image corresponding to each time point. This information is critical to describe the pyrolysis events observed.

\subsection{Processing of Visualization Data}

This section describes the experimental methodology used for the characterization of bubble birth rate, growth rate, size distribution, and bursting rate.

Control Volume: To study bubbling events within the intermediate liquid phase we defined the control volume as the initial volume occupied by the sample (Figure S1Appendix-A). Since we know the amount of sample used in the analysis (typically 0.5 $\mathrm{mg})$ and the actual density of both Organosolv lignin $\left(1,300 \mathrm{~kg} / \mathrm{m}^{3}\right)$ and sucrose $(1,590$ $\mathrm{kg} / \mathrm{m}^{3}$ ), it is possible to calculate the initial sample volume. This is the reference for the balance of populations. The cross-sectional area $\mathbf{A}$ is determined using the software ImajeJ [38]. The pixel area is estimated in the region marked by the red line (MakeBinary / Analyze- Measure area). The sample volume is irregular, for purpose of developing balance populations, an average height (ho) of the sample was estimated by dividing the volume by the area. 
Analysis of images: ImajeJ and MatLab R 2014 were used to process the videos. The image sequences were modified to improve the brightness and contrast, and in some cases the color map was modified to identify bubbles formed in greater detail. In all experiments the conversion of pixels to units of length was made by taking as reference the platinum filament diameter $(0.3556 \mathrm{~mm})$. Counting the bubbles in each image sequence was performed manually (see Figure S2 Appendix-A) using the image editor in MatLab.

On average, each video was made up of 2,000 frames. However, in the first 200 and last 700 frames it was not possible to observe bubbles. These frames correspond to the initial heating and char formation periods respectively. The remaining 1,100 intermediate frames are where most of the bubbling happened. We selected frames for the visualization and counting of bubbles, as shown later. For each frame we counted and measured each bubble using the command 'Measure distance' in Matlab; this information was stored in a MatLab script for further processing. Only bubbles that have clearly distinguishable and measurable edges were counted. As video capture speed is constant (125 fps), it is known the exact time of each image and the corresponding temperature value in both the quartz disc and sample. Matrices with bubble diameter vs time were stored in MatLab.

Nucleation and growth of bubbles were monitored in frames where they could be clearly tracked. The number of new bubbles was counted, and the number of bubble vectors vs time was constructed to describe the rate of nucleation of bubbles in each commodity.

Birth of new bubbles: For Organosolv lignin the only period where it is possible to visualize the birth of new bubbles without interference from the coalescence or death is between Frames $442-524(3.5 \mathrm{~s}-4.13 \mathrm{~s})$; for sucrose this region is between frames 514559 (4.11s-4.47s). In both cases we measured the number of bubbles formed per unit of area. Birth rate of bubbles is reported as the number of bubbles per $\mathrm{mm}^{2} \mathrm{~s}$. 
Bubble growth: It is difficult to track the size of each bubble because many of them interact, coalesce, and death. The growth of the bubbles is best studied in the video regions between frames 436-447 for Organosolv lignin and between frames 703-715 for sucrose. In this paper we assumed that the behavior of these bubbles is representative of the behavior of all the bubbles. Were fitted the bubble size vs. time into an Arrhenius model. Two graphs were made, one for bubble size vs time and the other for bubble growth rate $(\mathrm{d}(\mathrm{r}) / \mathrm{dt})$ vs time.

Bubble size distribution: In order to use this experimental information on population balances, histograms were built for each frame using the bubble diameters, assigning bin width as the square root of the number of data points. Using the Experimental Fitting Toolbox in MatLab R2014, several distribution functions were tested, finding the best fit to the histograms are log-normal type functions. The log-normal mean and standard deviation of the functions were calculated in each of the selected frames. For the population balance, using continuous functions for the accurate calculation of the partial derivatives was required. To achieve this, numerical interpolation (cubic) was made through time for the means and standard deviations of the Log-normal distribution functions to generate 1,000 time steps. For each time step we have a vector with the experimentally measured bubble diameters, and the distribution function evaluated for each diameter. A description of bubble growth and nucleation rate is made using the adjustable parameters. We can then obtain partial derivatives of the population balances (discretization methods) that correlate with each phenomenon.

\subsection{Mathematical model based on global population balance to predict microexplosion intensity and aerosol ejection intensity}

Global balance of values for bubbles within the liquid phase: A mathematical model based on population balances fed with experimental data (rate of bubble birth, rate of bubble growth, rate of bubble coalescence and death) is proposed to predict bubble bursting rate and aerosol ejection rate. Equation 1 is used to calculate bubble size distribution $[39,40]$. 


$$
\frac{\partial(\overline{\mathrm{f}}(\mathrm{t}, \mathrm{D}))}{\partial \mathrm{t}}-(\overline{\mathrm{f}}(\mathrm{t}, \mathrm{D}) \mathrm{v})=\frac{\partial}{\partial \mathrm{D}}(\dot{\mathrm{D}} \overline{\mathrm{f}}(\mathrm{t}, \mathrm{D}))+(\overline{\mathrm{Birth}}-\overline{\text { Death }})
$$

Where the function $\overline{\mathrm{f}}(\mathrm{t}, \mathrm{D})$ corresponds to the bubble distribution as a function of time per unit volume control and D is diameter of bubbles (found experimentally as described in Section 2.4). The function $\bar{f}(t, D)$ and descriptions of bubble growth rate and bubble transport are shown in Supplementary material (Appendix- A).

Knowing the experimental information distribution function and growth rate of bubbles, we can deconvolute the main phenomena involved in the dynamics of bubble formation, as shown in Figure S1 (Appendix-A). The spatial and temporal derivatives of the population balance (Eq. 1) are solved by discretization using approximations by finite differences. The intensity of aerosol ejection is defined in this paper as the volumetric flow of liquid droplets ejected from the liquid phase when gas bubbles collapse (bubble bursting). Paulsen et al. [41], Georgescu et al. [30], and Blanchard et al. [31] have proposed mathematical models for the aerosol formation mechanism. However the proposed models, although quite rigorous, only consider ejection due to the collapse of a single bubble in the gas-liquid interface, leaving aside the dynamics of bubbles in the liquid phase that contribute to global aerosol ejection. In this proposal, we will use an expression to estimate the intensity of ejection of aerosols based on the dynamics of formation and transport of gas bubbles within the liquid intermediate phase. This information is incorporated into bubble models to predict the fraction of high molecular weight oligomers (liquid intermediate) ejected as shown in Equation 11. The total volume of droplets ejected as aerosols is determined by integrating vs. devolatilization time as shown in Equation 2.

$$
\mathrm{V}_{\text {net }}\left(\mathrm{m}^{3}\right)=\frac{4 \pi}{3} \int_{\mathrm{o}}^{\mathrm{t}} \mathrm{I}_{\text {aerosoles }}\left(\frac{\mathrm{m}^{3} \text { aerosol }}{\mathrm{s}}\right) \mathrm{dt}
$$

Finally, the yield of aerosols, with respect to the initial mass of lignin or sucrose, is:

$$
\text { Yield }_{\text {aerosol }}=\frac{\text { Vnet } \rho_{1}}{\mathrm{~m}_{\mathrm{o}}} 100 \%
$$


In Appendix-A we present with more details all the mathematical expressions in the population balance.

\section{Results}

This section describes the experimental results first and then those obtained with the model. Experimental results include visualization and description of the behavior of lignin and sucrose during pyrolysis at average heating rates of $120{ }^{\circ} \mathrm{C} / \mathrm{s}$. The model was used to calculate the dynamics of bubbling within the liquid phase and aerosol ejection intensity.

\subsection{Global behaviors of Organosolv lignin and sucrose.}

Figure 3 shows the sequence of photographs taken in for Organosolv lignin and sucrose. The first temperature value within the parentheses corresponds to the surface of the disc, and the second is sample temperature in the middle of the sample where the thermocouple does not touch the disc.

\section{Figure 3}

For Organosolv lignin, the appearance of the first film of molten material is seen at 1.88 $s$ after the experiment began. The temperature at which melting of the sample initiates is $176.9{ }^{\circ} \mathrm{C}$ (see Frame A). These data are reasonable and close to those reported for Organosolv lignin by Dufour et al. $\left(150^{\circ} \mathrm{C}\right)$ [42] and Zhou et al. $\left(154^{\circ} \mathrm{C}\right)$ [43]. In frame $343(2.74 \mathrm{~s})$, the sample appears $100 \%$ melted. At this time, the average temperature of lignin is $241.75^{\circ} \mathrm{C}$; slight swelling can be seen, as well as the appearance of small bubbles of gas in the liquid with diameters of about 33 microns. The appearance of these microbubbles is indicative of vapor formation within the liquid phase by fragmentation reactions of $\beta-\mathrm{O}$ bonds to form phenols, alkoxy-ketones, and light gases [44]. Beyond this temperature, the whole dynamic of formation, growth, and death of bubble coalescence is evident. One can observe bubbles clearly between 2.99.25s. (Frames 362-1156). The main transformations of sucrose during pyrolysis are shown in Figure 3 Initially the specimen melts when it has reached $176^{\circ} \mathrm{C}$, and is completely melted at $225^{\circ} \mathrm{C}$ (Box B). From this point on, the dynamics of growth, 
coalescence, and death of bubbles can be described graphically as discussed in the next section. At the end, a carbonaceous residue from re-polymerization reactions and dehydration of fructose and glucose is produced.

\subsection{Birth rate of bubbles in the liquid phase: Organosolv lignin}

The birth of bubbles in Organosolv lignin can be seen in Figure 4. Once a group of molecules exceed a minimum threshold energy (boiling point), the cluster is detached from the body of liquid and appears a gas-liquid interface. In the case of pyrolysis the vapors can be produced by chemical reactions or by the vaporization of small molecules (e.g. moisture evaporation).

\section{Figure 4}

Experimental analysis of the bubbling with number of bubbles and nucleation rates can be seen in Figure S5 (Appendix-A), where two regimes of nucleation are evident. The first regime $<430 \mathrm{~ms}$ (Frames A-D, Stage I) is where the bubble birth rate is low. Only six bubbles have formed in the displayed area. In this first stage, the gas cluster formed by fragmentation of volatile must overcome the barrier of the surface tension to form bubbles. This barrier begins to become less and less important as the temperature increases (Frames F-H) since the surface tension decreases, facilitating birth and growth of new bubbles (Stage II). The maximum bubble birth rate was observed once the sample has reached $301{ }^{\circ} \mathrm{C}$. From there, due to the intensive bubbling, it was not possible to distinguish any separate phenomenon.

The molecular theory of nucleation describes the behavior of birth of bubbles in terms of thermodynamic properties of bulk [45] as shown in Equation 4.

$$
\mathrm{J}=\mathrm{N}_{\mathrm{o}} \mathrm{e}^{-\frac{\Delta \mathrm{E}_{\text {cri }}}{\mathrm{k}_{B} \mathrm{~T}}}
$$

In the above equation $\mathrm{J}$ is the nucleation rate, $\mathrm{N}_{\mathrm{o}}$ is a frequency factor for occurrence of new bubbles, $\Delta \mathrm{E}_{\text {cri }}$ is the minimum free energy required to form the first cluster gas, $k_{B}$ 
is the Boltzmann constant, and $\mathrm{T}$ is the temperature of the liquid phase. By fitting the data, the frequency factor $\left(\mathrm{N}_{\mathrm{o}}\right)$ is $6.22 * 10^{1}$ bubbles $\mathrm{ms}^{-1} \mathrm{~mm}^{-2}$ and the minimum free energy is $43.317 \mathrm{~kJ} \mathrm{~mol}^{-1}$.

\subsection{Birth rate of bubbles in the liquid phase: Sucrose}

The nucleation process begins with the increase of internal energy of the bubble, which is proportional to the diameter thereof. The thermodynamic driving force for nucleation and growth of bubbles is the vapor pressure of the volatiles produced. During fast pyrolysis of cellulose and sugars, the major compounds released into the gas phase are permanent gases $\left(\mathrm{H}_{2}, \mathrm{CO}_{2}, \mathrm{CO}\right)$, organic acids (acetic, formic), furfural, 5-HMF, and glyoxal. The anhydrosugars formed are levoglucosan, cellobiosan, among others; they have very high boiling points and possibly are not part of the gas inside the bubble. Instead, these sugars can be ejected as aerosols or evaporated directly from the liquid phase. Figure 5 shows the sequence of pictures describing the birth, growth and coalescence of bubbles in the liquid intermediate phase of sucrose pyrolysis.

\section{Figure 5}

Similar to lignin, nucleation of sucrose bubbles is very fast and difficult to monitor. Bubbles merge very quickly with other bubbles, making it difficult to count the birth of new bubbles. However, between frames 514-559, it was possible to follow the birth of bubbles in isolation. Only seven frames in which the changes shown in the number of bubbles were observed. The bubble birth rate is constant (see Figure S5-Appendix-A). In the studied area and times used to estimate the nucleation, the number of bubbles per $\mathrm{mm}^{2}$ increases linearly. This behavior is that in the range studied time, the sample temperature is practically constant (only increases $14{ }^{\circ} \mathrm{C}$ ). As for Organosolv lignin, the Arrhenius expression (equation 4) was fit to the experimental data to estimate the nucleation rate at any time $\mathrm{t}$. The results show that $\Delta \mathrm{E}_{\mathrm{cri}}$ is $69.45 \mathrm{~kJ} \mathrm{~mol}^{-1}$ and $\mathrm{N}_{\mathrm{o}}$ is $2.86 * 10^{5}$ bubbles $\mathrm{ms}^{-1} \mathrm{~mm}^{-2}$. These results should be viewed as a starting point, since this is for lower temperature and bubble nucleation is certainly more intense at higher temperatures, where it is difficult to track them with our equipment.

\subsection{Bubble growth of Organosolv lignin and sucrose}


It is difficult to track each bubble to estimate its growth rate. Once formed bubbles interact with others to coalesce and die. For Organosolv lignin, a single bubble isolated from the others was identified between the frames 436-447, which we could track over time (see Figure 6). For sucrose, a solitary bubble was tracked between frames 703-713 (80 ms). In this short period of time the temperature of the disc and the sample are on average $440{ }^{\circ} \mathrm{C}$ and $275^{\circ} \mathrm{C}$, respectively.

\section{Figure 6}

Due to lack of data on the intermediate liquid properties (density, surface tension, chemical reaction rate, viscosity), it is difficult to propose and solve a phenomenological level model that describes the growth of bubbles. Thus, we used experimental data that was parametrically adjusted assuming an Arrhenius behavior of order $n$ for both sucrose and lignin in order to predict the growth rate (Appendix- A).

By comparison, the growth rates of Organosolv lignin, and sucrose, are actually on the same order of magnitude but sucrose has about a 2-3 times larger growth rate. The rate of bubble growth is dominated by many forces that interact simultaneously (viscous forces, drag forces, surface tension, etc.). The differences in behavior between the growth rate of the Organosolv lignin and sucrose may be related to changes in temperature depending on the physicochemical properties such as viscosity and surface tension and also on the rate of volatile matter formation.

\subsection{Distribution of the bubbles within the liquid phase of Organosolv lignin}

Histograms were created to visualize the distributions of bubble diameters in bins (see Figure 7). The number of intervals (bins) was set to the square root of the number of total data points. The distribution at each time step was fit to a log-normal distribution curve. Initially, all the bubbles are of small diameter with a mean of $183 \mu \mathrm{m}$.

In the range of temperatures studied, two regimes are observed. In the first 4 images (Frames A-D), the number of bubbles is approximately constant (50 bubbles), but the distribution is becoming wider (increased standard deviation). This indicates that individual bubbles grow and increase in size. Bubbles escaping the system will likely be 
replaced by new bubbles but the system is unlikely to achieve "steady state" since it is a small batch experiment. This temperature range $\left(250-380{ }^{\circ} \mathrm{C}\right)$ is known to have the maximum rate of volatiles release in lignin. The main products are alkoxy phenols, alkoxylated phenol-ketone products as the $\beta-\mathrm{O}-4$ lignin bonds break [44]. According Dufour et al. $[42,46]$, the viscosity of the lignin liquid intermediate increases in this temperature regime.

\section{Figure 7.}

In the second regime (Frames E-H), the total number of observable bubbles decreases continuously from 40 to 6 bubbles; the death and bursting rates are higher than the birth rate of bubbles. In this region dehydration reactions and crosslinking should be very intense, promoting the production of char (i.e. re-condensation of the melt phase) which dramatically increases the viscosity of the liquid intermediate phase as outgassing is reduced. After $9.25 \mathrm{~s}$, no new bubbles are formed.

\subsection{Distribution of the bubbles within the liquid phase of sucrose.}

The same histograms were produced with the data for sucrose, which also exhibited Log-normal distribution (see Figure 8).

\section{Figure 8}

At first, a few gas bubbles with an average diameter of $700 \mu \mathrm{m}$ are formed (A-C) as a result of fragmentation or dehydration reactions. In this time interval, both viscosity and surface tension of the liquid phase should be rather high, slowing the birth and growth of bubbles. After $5 \mathrm{~s}$ (boxes D-F), the bubbles have a greater diameter, and the frequency of formation also increases, partly because the surface tension and viscosity decreased by increase in temperature, this favors the birth rate and growth bubble directly. The rate of bubble growth and the birth rate are important in this period, in contrast to death rates and bursting (see Figure 8). There are abrupt changes in the distribution functions (boxes F-G) caused by swelling and large bursting bubbles, after which new bubbles coalesce with smaller. Finally, as with lignin, the liquid phase solidifies due to dehydration and polymerization reactions which increase viscosity, 
limiting formation and growth of bubbles. The distribution is characterized by small diameter bubbles which give porous texture end of carbonized. Importantly, after $7 \mathrm{~s}$ (Frame 916), the liquid phase begins to become dark because of the polymerization reactions. The distributions of bubbles in the H-J boxes take into account only the bubbles seen in the outer surface of the molten phase.

\subsection{Population balance to predict bubble bursting rate, bubbles coalescence, and aerosol ejection intensity}

In this section we describe the net rate of birth and death of bubbles using our population balance model. The distribution functions for bubble birth and death and the rate of bubble growth obtained in the previous section are used.

Birth and death rates of bubbles: In Figure 9, the deconvolution of the distribution function is shown. The coalescence and death events are very intense for very small bubbles (up to $60 \mu \mathrm{m}$ ). These results have been reported by other investigators $[47,48]$ for bubbles in viscous media. The curves shown in Frames $\mathrm{A}$ and $\mathrm{C}$ have positive and negative peaks at each time step. When the peak is positive (birth rate $>$ death rate), bubble nucleation or fragmentation predominates. When curves are negative (birth rate $<$ death rate), bubble coalescence dominates. It is quite interesting to note that for each time step, coalescence is favored for smaller bubbles in phase liquid for Organosolv lignin; however the trend is opposite for sucrose (Frame-C) where the probability of bubble coalescence is inversely proportional to the bubble diameter [39,40]. Similarly, the larger bubbles tend to fragment into multiple new bubbles. It is interesting to note the behavior of the curve in Frame A (9.5 s), where there is a huge positive peak for small diameter bubbles but it is zero for diameters $>12 \mu \mathrm{m}$.

As mentioned previously, when the lignin melt phase exceeds $250{ }^{\circ} \mathrm{C}$ it begins to resolidify, altering the dynamics of bubbles inside. As the viscosity increases, the chances of meeting between bubbles decreases considerably [49]. Under these conditions very small bubbles grow slowly and are virtually static. These bubbles are responsible for the final formation of cenospheres (hollow spheres) after pyrolysis. Figure $9 \mathrm{~B}$ and D, represent the net rate of birth and death averaged bubble. This is obtained by totaling all 
bubble distributions at each time step. Analyzing the overall performance of Figures 9 B and $\mathrm{D}$, we note that in the first $9.5 \mathrm{~s}$, the death rate of bubbles is the predominant phenomenon (the rate of death by fragmentation and nucleation is more intense than bubble coalescence). At the end, the liquid phase is very viscous as the liquid polycondenses to form a carbonaceous residue.

\section{Figure 9}

Bubble Bursting: Experimentally, for lignin and sucrose it is difficult to track the aerosols as they leave the liquid phase. This phenomenon is quite fast and difficult to capture with our fast speed camera. However, in Figure 10 a sequence of images acquired every $8 \mathrm{~ms}$ shows gas bursting. For Organosolv lignin, the frames 389-527, show the morphological changes of the liquid surface once the bubbles collapse. Although there are many bubbles, it is only possible to see substantial changes in the central bubble, which is larger. In frames B-E, the formation and growth of a bubble in the lower right is observed. This bubble collapses (F), and deforms the entire surface of the liquid phase, by shrinking $(\mathrm{G}-\mathrm{H})$. This process is continuous and regular, until re-condensation reactions.

Frames J-N show a region of high curvature generated by the collapse of the bubble in Frame I. At the beginning is a large opening, which quickly closed (Frames KI). Throughout the video sequence the formation of jets is not directly observed (nor in any videos taken). Previous studies have shown that for a jet to be formed, the Ohnesorge (Oh) number should not exceed a certain critical value [28,50]. This number is the ratio of viscous forces to inertial forces and superficial tension.

$$
O h=\frac{\mu_{l}}{\sqrt{\rho_{l} \Omega R}}
$$

Systems with Ohnesorge number (Oh) over 0.037, do not produce jets because the capillary forces that direct the movement of the liquid surface are damped by viscous forces [50]. It will be interesting to have an estimate of what value it has for lignin oligomers. The Bond number is another parameter to consider when there is no formation of jets because gravity is important, altering the balance, shape, and movement. 
Figure 10

Using data of viscosity $(0.004 \mathrm{~Pa} \cdot \mathrm{s})$, surface tension $\left(0.015 \mathrm{~N} \mathrm{~m}^{-1}\right)$ reported in Hwang et al. [51] for tar coal at high temperatures and the estimated density of the liquid phase $\left(\rho_{l}=760.15 \mathrm{~kg} / \mathrm{m}^{3}\right)$ the bubble diameter was estimated as $1.025 \mathrm{~mm}$ (see section 2.4$)$.

Figure 11 shows the sequence of frames that describe the collapse of bubbles within the liquid phase produced during the pyrolysis of sucrose. Frames A-D show the destruction of a large bubble (box A) and formation of a toroid shaped cavity, which begins to contract gradually. As the shrinkage continues, gases are released due to a difference between the vapor pressure and atmospheric pressure. In this sequence the formation of jets was not appreciated. However, in Frames E-H a small jet is formed and in Frame $\mathrm{H}$ an aerosol droplet is released. The sequence of generation and collapse of a bubble $(\mathrm{t}<<$ $8 \mathrm{~ms}$ ) produces a depression in the surface; a liquid column extends from $200 \mu \mathrm{m}$ (Frame F) to $300 \mu \mathrm{m}$ (Frame G) measured from the surface of the drop of liquid. The fragmentation of this jet produces an aerosol with a $117 \mu \mathrm{m}$ diameter.

\section{Figure 11}

A second event occurs after $8 \mathrm{~ms}$ (Frame I) wherein the central bubble collapses, releasing aerosols very small in diameter $(12 \mu \mathrm{m})$. This has also been reported by other investigators $[1,10]$. During this stage, many small aerosols are released in all directions at a very high speed, making it difficult to capture them, even with $1000 \mathrm{fps}$ [1]. A new jet is generated between frames I and K. A jet of $888 \mu \mathrm{m}$ (Frame J) subsequently contracts to $316 \mu \mathrm{m}$ releasing two aerosol droplets $(166 \mu \mathrm{m}$ diameter and $149 \mu \mathrm{m})$. The number of aerosols released by fragmentation of jets is directly linked to the diameter of the mother bubble. The relationship between the size of aerosol and mother bubble is on average close to those reported elsewhere $[1,29,30]$. Some researchers have proposed empirical correlations to relate these two variables [11,21,22,50]. Using equation 6, proposed by Zhang et al. [29] for a mother bubble of 890 microns (Frame F), the number of theoretical aerosols formed is 2.7 , very close to the two aerosols experimentally observed. Such correlations becomes important when considering 
particle level models, as they are the bridge connecting the bubbling events with the release of aerosols. Figure 21 shows the theoretical behavior of the predicted output bubbles with the methodology described in section 2.5 for both Organosolv lignin and sucrose.

\section{Figure 12}

Figure 12 clearly shows that the bubble bursting rate is fluctuating due to the balance between formation and explosion of bubbles combined with liquid relaxation. Subplot A shows changes in bursting rate versus time and bubble diameter for lignin. For example, the black curve $(\mathrm{t}=4.5 \mathrm{~s})$ represents the distribution of bursting rates of bubbles in $4.5 \mathrm{~s}$. On the same curve, the point of intersection of the two dotted lines represents the output rate of $0.15 \mathrm{~mm}$ diameter bubbles in $4.5 \mathrm{~s}$. From the $\mathrm{A}$ and $\mathrm{C}$ curves, we can infer that at low times when the generation of steam is very intense, gas bubbles tend to break while they are very small; when generation of vapors slows down, the bubbles tend to break at larger diameters. In the region where there is intense release of volatiles, the viscosity of the liquid phase increases dramatically so the bubbles require more energy to breach the surface. In these stages bubbles increase their internal energy by coalescing with other bubbles or by expansion of internal gas. The rate of bubble bursting in lignin is highest for bubbles with diameters smaller than $200 \mu \mathrm{m}, 500$ $\mu \mathrm{m}$ being the maximum. In sucrose however, the bubble bursting rate is larger, contributing to larger bubbles (> $200 \mu \mathrm{m})$.

Subplots B and D shows the total intensity of bursting for both materials. Total bursting rate of bubbles was determined by adding at each instant of time, exit rates of bubbles of different diameters present in the distribution function. Bursting intensity is greater for the liquid phase of the Organosolv lignin, which produces more bubbles, but smaller bubbles compared to sucrose. As a result, the rate of ascent of the bubbles increases, reducing the residence time within the liquid phase. In our proposal, the bubble bursting frequency factor $(1 / \mathrm{s})$, is linked to $\mathrm{vb} / \mathrm{h}$ ratio, which determines the inverse of the residence time of the bubbles within the liquid. This is a first approximation which we consider relevant and valid for the study of aerosol ejection due to bubble collapse in the liquid phase during pyrolysis of biomass. This phenomenon is quite complex; other 
researchers have proposed correlations depending on the size of bubbles and fluid properties to estimate the bursting frequency of bubbles $[8,9,12,15,52]$

Aerosol ejection intensity: The collapse of bubbles within the liquid phase of pyrolysis of biomass and / or pseudo-components is the driving force for ejecting aerosols [3]. Discussion related to aerosol ejection is of vital importance in the field of biomass fast pyrolysis. This phenomenon may explain the presence of high molecular weight compounds in the bio-oil as oligomeric anhydro-sugars and pyrolytic lignin $[4,5,53]$. The actual content of oligomers in bio-oils is not well known. The oligomers derived from lignin can be easily separated by cold water precipitation, however we do not have methods today to predict the oligomers derived from cellulose. By understanding the formation of the liquid phase during devolatilization, one can theoretically predict the amount of these compounds which can be ejected. In this paper, we propose a simple methodology to predict the rate of thermal ejection based on the dynamics of bubble formation. In our proposal, aerosol distribution is directly related to the bubbling properties. The coalescence of bubbles, fragmentation, growth, evaporation, and other phenomena can alter the final size distribution of aerosols [54]. Research related to the ejection of aerosols during pyrolysis of biomass is still in its infancy and requires greater efforts to consolidate experimental and theoretical results. Figure 13 shows the aerosol distribution function of time and diameter of the aerosol droplets ejected both Organosolv lignin and sucrose.

\section{Figure 13}

Subplots A-D show the distribution of the aerosol ejection rate at different times depending on the diameter of aerosol. For both materials, the maximum rate of ejection occurs with small diameter droplets $(<10 \mu \mathrm{m})$. Dauenhauer et al. [3] found similar sizes for aerosols ejected during the fast pyrolysis of cellulose.

The $\mathrm{B}$ and $\mathrm{E}$ subplots represent the total aerosol ejection rate per unit volume of sample. The aerosol ejection intensity of Organosolv lignin higher after $6.3 \mathrm{~s}$ where bubbles are larger than $0.1 \mathrm{~mm}$. As discussed, two mechanisms can produce aerosols from sucrose. In each of these events, the distribution function is centered on a bubble diameter of $0.2 \mathrm{~mm}$ (see Figure 13). The $\mathrm{C}$ and $\mathrm{F}$ subplots represent the total volume of 
aerosols accumulated over time. This data is useful to estimate the quantity of aerosols generated per mg of sample used. The amount of sample used for the experiment was $0.5 \mathrm{mg}$, and we assume aerosols of sucrose and lignin have a density of $1000 \mathrm{~kg} / \mathrm{m}^{3}$.

The model predicts aerosol ejection yields $21.18 \% \mathrm{w} / \mathrm{w}$ for devolatilization of Organosolv lignin and $17.40 \% \mathrm{w} / \mathrm{w}$ for sucrose. Yields of lignin oligomers have been reported in the literature on the order of 8 and $30 \mathrm{wt}$. \% from pyrolysis of biomass and 14-24 wt. \% for lignin [55]. For cellulose, yields of oligomer anhydrosugars ( $>2$ degree of polymerization) are on the order of $8 \%$ and $400{ }^{\circ} \mathrm{C}[56]$, and $20 \%(2<\mathrm{Dp}<7)$ for Avicel cellulose [53]. This reveals that our results are in the correct range compared with experimental data.

\section{Conclusions}

A new methodology has been proposed to describe of the dynamics of bubble formation in Organosolv lignin and sucrose that combines fast speed visualization (125fps) with mathematical modeling. The model uses a population balance to theoretically predict overall rates of bubble birth and death, bubble bursting, and aerosol ejection. Experimentally, we observed that gas bubbles follow a log-normal distribution versus bubble size within the liquid intermediate phase for both materials. This distribution function changes over time due to increased viscosity from resolidification reactions that generate char. The model predicts aerosol ejection yields of $21.18 \% \mathrm{w} / \mathrm{w}$ from Organosolv lignin and $17.40 \% \mathrm{w} / \mathrm{w}$ from sucrose during pyrolysis. Future work needs to be done to study aerosol ejection in real biomass particles, as well as cellulose and hemicellulose using novel methodologies.

Acknowledgment: The authors are grateful to Colciencias for economic support for the development of the doctoral thesis of Mr. Jorge Montoya. This research was also funded by the Washington State Agricultural Research Center (NIFA-Hatch-WNP00701) and the National Science Foundation (CBET-1434073, CAREER CBET-1150430) for which the authors are very grateful. We also thank Jonathan Lomber for the support provided. 
Nomenclature (Include the terms used in the Supplementary information): 


\begin{tabular}{|c|c|}
\hline$t$ & Time (s) \\
\hline $\bar{f}(t, D)$ & Average Distribution Function of Bubbles (\#bubbles $/ \mathrm{s} \mathrm{m}^{3}$ ) \\
\hline $\mathrm{D}$ & Bubble Diameter (mm) \\
\hline $\mathrm{v}$ & Bubble Velocity $(\mathrm{m} / \mathrm{s})$ \\
\hline$\dot{D}$ & Bubble Growth Rate (m/s) \\
\hline$\sigma$ & Standard Deviation of Log-Normal Distribution \\
\hline$\gamma$ & Mean Value of Log-Normal Distribution \\
\hline $\mathrm{H}$ & Particle height (m) \\
\hline $\mathrm{G}$ & Gravity Constant $\left(\mathrm{m} / \mathrm{s}^{2}\right)$ \\
\hline $\mathrm{R}$ & Bubble Size (mm) \\
\hline$\rho_{l}$ & Liquid Density $\left(\mathrm{kg} / \mathrm{m}^{3}\right)$ \\
\hline$\rho_{b}$ & Bubble Density $\left(\mathrm{kg} / \mathrm{m}^{3}\right)$ \\
\hline$\mu_{l}$ & Liquid Dynamic Viscosity (Pas) \\
\hline $\mathrm{k}$ & Growth Constant $\left(\mathrm{ms}^{-1}\right)$ \\
\hline $\mathrm{n}$ & Order of Growth Law \\
\hline$R_{\text {aerosol }}$ & Aerosol Size (mm) \\
\hline$I_{\text {aerosol }}$ & Aerosol Ejection Intensity $\left(\mathrm{m}^{3} / \mathrm{s}\right)$ \\
\hline$N_{\text {aerosol }}$ & Number of Aerosols \\
\hline$N_{\text {bubbles }}$ & Number of Bubbles \\
\hline$V_{\text {control }}$ & Volume of control \\
\hline$V_{\text {control }}$ & Volume of control \\
\hline $\mathrm{V}$ & Particle Volume $\left(\mathrm{m}^{3}\right)$ \\
\hline$N_{0}$ & Constant of Number of bubbles $/ \mathrm{s} \mathrm{m}^{3}$ in Nucleation \\
\hline $\mathrm{J}$ & Bubbles Nucleation Rate (\# Bubbles/s m³) \\
\hline$k_{b}$ & Boltzmann Constant $\left(\mathrm{kJ} \mathrm{K}^{-1}\right)$ \\
\hline $\mathrm{T}$ & Temperature (K) \\
\hline$\Delta E_{c r i}$ & Minimum Free Energy to Form a Single Bubble (kJ/mol) \\
\hline oh & Ohnesorge number \\
\hline$\Omega$ & Surface Tension $\left(\mathrm{N} / \mathrm{m}^{2}\right)$ \\
\hline$B_{o}$ & Bond Number \\
\hline Vneto $_{\text {aerosol }}$ & Total Aerosol Volume $\left(\mathrm{m}^{3}\right)$ \\
\hline$\overline{F a}\left(t, V_{a}\right)$ & Average Distribution Function of Aerosol (\#Aerosol/s $\mathrm{m}^{3}$ ) \\
\hline$V_{a}$ & Aerosol Volume $\left(\mathrm{m}^{3}\right)$ \\
\hline Yield $_{\text {aerosol }}$ & Aerosol Yield (kg aerosol / kg initial sample) \\
\hline$L$ & Lignin density ( $\mathrm{kg}$ lignin / m initial sample) \\
\hline$I L$ & Intermediate Liquid density ( $\mathrm{kg} \mathrm{IL} / \mathrm{m}^{3}$ initial sample) \\
\hline
\end{tabular}




$\begin{array}{cl}A & \text { Aerosol density (kg Aerosol } / \mathrm{m}^{3} \text { initial sample) } \\ P L & \text { Pyrolytic Lignin density }\left(\mathrm{kg} \mathrm{PL} / \mathrm{m}^{3} \text { initial sample) }\right. \\ \text { Char } & \text { Char density }\left(\mathrm{kg} \mathrm{Char} / \mathrm{m}^{3} \text { initial sample) }\right. \\ \text { Gas } & \text { Gas density }\left(\mathrm{kg} \mathrm{Gas} / \mathrm{m}^{3} \text { initial sample) }\right. \\ L M & \text { Lignin Monomers density }\left(\mathrm{kg} \mathrm{LM} / \mathrm{m}^{3} \text { initial sample) }\right. \\ \rho_{\text {lignin }} & \text { Lignin Density }\left(\mathrm{kg} / \mathrm{m}^{3}\right) \\ C p & \text { Heat Capacity of Lignin }(\mathrm{kJ} / \mathrm{kg} \mathrm{K}) \\ h_{\text {ext }} & \text { External Heat Transfer Coefficient }\left(\mathrm{kW} / \mathrm{m}^{2} \mathrm{~K}\right) \\ \text { Area } & \text { Area of Transversal Section of the Sample }\left(\mathrm{m}^{2}\right) \\ T_{f} & \text { Final Temperature }(\mathrm{K}) \\ K_{i} \mathrm{i}=1,2,3,4,5 & \text { Kinetics Coefficients }\left(\mathrm{s}^{-1}\right) \\ K_{o} & \text { Kinetic Frequency Factor }\left(\mathrm{s}^{-1}\right) \\ E_{a} & \text { Energy of Activation }(\mathrm{kJ} / \mathrm{mol}) \\ \gamma & \text { Gases Yield (kg Gases } / \mathrm{kg} \mathrm{PL)} \\ \Lambda & \text { Lignin Monomers Yield }(\mathrm{kg} \mathrm{LM} \mathrm{/} \mathrm{kg} \mathrm{PL)}\end{array}$

\section{References}

[1] P. Teixeira, A.R., Mooney, K.G., Kruger, J.S., Williams, C.L., Suszynski, W.J., Schmidt, L.D., Schmidt, D.P. and Dauenhauer, Aerosol generation by reactive boiling ejection of molten cellulose, Energy Environ. Sci. 4 (2011) 4306.

[2] P.J. Dauenhauer, D.G. Vlachos, M.S. Mettler, Top ten fundamental challenges of biomass pyrolysis for biofuels, Energy Environ. Sci. 5 (2012) 7797.

[3] P. J. Dauenhauer, Joshua L Colby, Christine M Balonek, Wieslaw J Suszynski, Reactive boiling of cellulose for integrated catalysis through an intermediate liquid, Green Chem. 11 (2009) 1555-1561.

[4] M. Le Bras, J. Yvon, S. Bourbigot, V. Mamleev, The facts and hypotheses relating to the phenomenological model of cellulose pyrolysis, J. Anal. Appl. 
Pyrolysis. 84 (2009) 1-17.

[5] S. Zhou, M. Garcia-Perez, B. Pecha, A.G. McDonald, R.J.M. Westerhof, Effect of particle size on the composition of lignin derived oligomers obtained by fast pyrolysis of beech wood, Fuel. 125 (2014) 15-19.

[6] J.R. Grace, T. Wairegi, J. Brophy, Break-up of drops and bubbles in stagnant media, Can. J. Chem. Eng. 56 (1978) 3-8.

[7] S. Saka, M. Asmadi, H. Kawamoto, Gas- and solid/liquid-phase reactions during pyrolysis of softwood and hardwood lignins, J. Anal. Appl. Pyrolysis. 92 (2011) $417-425$.

[8] K. Butler, A numerical model for combustion of bubbling theroplastic materials in microgravity, (2002) 70.

[9] D.E. Spiel, The number and size of jet drops produced by air bubbles bursting on a fresh water surface, J. Geophys. Res. 99296 (1994) 289-10.

[10] M.K. Tripathi, K.C. Sahu, R. Govindarajan, Dynamics of an initially spherical bubble rising in quiescent liquid, Nat. Commun. 6 (2015) 6268.

[11] B.R. Fu, C. Pan, Bubble growth with chemical reactions in microchannels, Int. J. Heat Mass Transf. 52 (2009) 767-776.

[12] S. Myongsook, W.A. Oh, P.J.B. Howard, An experimental and modeling study of softening coal pyrolysis, AIChE J. 35 (1989).

[13] F.A. Williams, Ignition and burning of single liquid droplets, Acta Astronaut. 12 (1985) 547-553.

[14] D.E. Kim, D.I. Yu, D.W. Jerng, M.H. Kim, H.S. Ahn, Review of boiling heat transfer enhancement on micro/nanostructured surfaces, Exp. Therm. Fluid Sci. 66 (2015) 173-196.

[15] S. Das, D.S. Kumar, S. Bhaumik, Experimental study of nucleate pool boiling heat transfer of water on silicon oxide nanoparticle coated copper heating surface, Appl. Therm. Eng. 96 (2016) 555-567.

[16] M. Shojaeian, A. Koşar, Pool boiling and flow boiling on micro- and nanostructured surfaces, Exp. Therm. Fluid Sci. 63 (2015) 45-73.

[17] C.K. Law, Recent advances in droplet vaporization and combustion, Prog. Energy Combust. Sci. 8 (1982) 171-201.

[18] M.M. Avulapati, L.C. Ganippa, J. Xia, A. Megaritis, Puffing and microexplosion of diesel-biodiesel-ethanol blends, Fuel. 166 (2016) 59-66.

[19] A.R. Teixeira, R.J. Hermann, J.S. Kruger, W.J. Suszynski, L.D. Schmidt, D.P. 
Schmidt, P.J. Dauenhauer, Microexplosions in the upgrading of biomass-derived pyrolysis oils and the effects of simple fuel processing, ACS Sustain. Chem. Eng. 1 (2013) 341-348.

[20] S. Takeda, M. Fuchihata, T. Ida, Observation of microexplosions in spray flames of light oil-water emulsions (3rd report, influence of the diameter of dispersed water droplets on the spray flame structure), Trans. Japan Soc. Mech. Eng. Ser. B. 74 (2008) 1649-1654.

[21] H.Z. Sheng, L. Chen, Z.P. Zhang, C.K. Wu, C. An, C.Q. Cheng, The droplet group microexplosions in water-in-oil emulsion sprays and their effects on diesel engine combustion, Symp. Combust. 25 (1994) 175-181.

[22] M.Y. Khan, Z.A.A. Karim, a. R.A. Aziz, I.M. Tan, Experimental investigation of microexplosion occurrence in water in diesel emulsion droplets during the Leidenfrost effect, Energy \& Fuels. 28 (2014) 7079-7084.

[23] M. Garcia-Perez, P. Lappas, P. Hughes, L. Dell, a Chaala, D. Kretschmer, C. Roy, Evaporation and Combustion Characteristics of Biomass Vacuum Pyrolysis Oils, IFRF Combust. J. 200601 (2006) 1-27.

[24] C. Di Blasi, Modelling the fast pyrolysis of cellulosic particles in fluid-bed reactors, Chem. Eng. Sci. 55 (2000) 5999-6013.

[25] C. Di Blasi, Physico-chemical processes occurring inside a degrading twodimensional anisotropic porous medium, Int. J. Heat Mass Transf. 41 (1998) 4139-4150.

[26] S.-S. Hou, F.M. Rizal, T.-H. Lin, T.-Y. Yang, H.-P. Wan, Microexplosion and ignition of droplets of fuel oil/bio-oil (derived from lauan wood) blends, Fuel. 113 (2013) 31-42.

[27] Y. Sezen, Internal mass transfer considerations during the pyroly sis of an isolated spherical softening coal particle, Lnt. J. Heat Mass Transf. 32 (1989) 1992-1987.

[28] J.S. Lee, B.M. Weon, S.J. Park, J.H. Je, K. Fezzaa, W.-K. Lee, Size limits the formation of liquid jets during bubble bursting., Nat. Commun. 2 (2011) 367.

[29] J. Zhang, J.J.J. Chen, N. Zhou, Characteristics of jet droplet produced by bubble bursting on the free liquid surface, Chem. Eng. Sci. 68 (2012) 151-156.

[30] S.C. Georgescu, J.L. Achard, É. Canot, Jet drops ejection in bursting gas bubble processes, Eur. J. Mech. B/Fluids. 21 (2002) 265-280.

[31] D.C. Blanchard, The size and height to which jet drops are ejected from bursting 
bubbles in seawater, J. Geophys. Res. 94 (1989) 10999.

[32] J. Shen, X.-S. Wang, M. Garcia-Perez, D. Mourant, M.J. Rhodes, C.-Z. Li, Effects of particle size on the fast pyrolysis of oil mallee woody biomass., Fuel. 88 (2009) 1810-1817.

[33] P.N. Ciesielski, M.F. Crowley, M.R. Nimlos, A.W. Sanders, G.M. Wiggins, D. Robichaud, B.S. Donohoe, T.D. Foust, Biomass particle models with realistic morphology and resolved microstructure for simulations of intraparticle transport phenomena, Energy and Fuels. 29 (2015) 242-254.

[34] M. Garcia-Perez, S. Wang, J. Shen, M. Rhodes, W.J. Lee, C.Z. Li, Effects of temperature on the formation of lignin-derived oligomers during the fast pyrolysis of Mallee woody biomass, Energy and Fuels. 22 (2008) 2022-2032.

[35] R.J. Westerhof, Refining fast pyrolysis of biomass, $\mathrm{PhD}$ thesis University of Twente, 2011.

[36] T.J. Hilbers, Z. Wang, B. Pecha, R.J.M. Westerhof, S.R.A. Kersten, M.R. PelaezSamaniego, M. Garcia-Perez, Cellulose-Lignin Interactions during slow and fast pyrolysis. Journal of Analytical and Applied pyrolysis. Vol. 114, 2015, 197-2007

[37] M. Pelaez Samaniego, V. Yadama, M. Garcia-Perez, E. Lowell, A.G. McDonald A, Effect of temperature during wood torrefaction on the formation of liquid intermediates. Journal of Analytical and Applied Pyrolysis 109 (2014) 222-233

[38] S.J. Abramoff, M.D.; Magalhães, Paulo J.; Ram, Image processing with ImageJ, Biophotonics Int. 11 (2004) 36-42.

[39] D. Ramkrishna, Population Balances, Academic Press, 2000.

[40] N.N. Rao, Simulations for modelling of particulate processes using discrete particle model (DPM), Otto-von-Guericke Universität Magdeburg, 2009.

[41] M.S. Mettler, S.H. Mushrif, A.D. Paulsen, A.D. Javadekar, D.G. Vlachos, P.J. Dauenhauer, Revealing pyrolysis chemistry for biofuels production: Conversion of cellulose to furans and small oxygenates, Energy Environ. Sci. 5 (2012) 54145424

[42] A. Dufour, M. Castro-Diaz, N. Brosse, M. Bouroukba, C. Snape, The origin of molecular mobility during biomass pyrolysis as revealed by in situ 1H NMR spectroscopy, ChemSusChem. 5 (2012) 1258-1265.

[43] M. Zhou, S., Pecha, B., van Kuppevelt, M., McDonald, A.G. and Garcia-Perez, Slow and fast pyrolysis of Douglas- Fir Lignin:Importance of liquid intermediate formation on distribution of products, Biomass and Bioenergy. (2014) 398-409. 
[44] V.B.F. Custodis, C. Bährle, F. Vogel, J.A. van Bokhoven, Phenols and aromatics from fast pyrolysis of variously prepared lignins from hard- and softwoods, J. Anal. Appl. Pyrolysis. 115 (2015) 214-223.

[45] M. Blander, Bubble nucleation in liquids, Adv. Colloid Interface Sci. 10 (1979) $1-32$.

[46] A. Dufour, M. Castro-Díaz, P. Marchal, N. Brosse, R. Olcese, M. Bouroukba, C. Snape, In Situ Analysis of Biomass Pyrolysis by High Temperature Rheology in Relations with 1H NMR, Energy \& Fuels. 26 (2012) 6432-6441.

[47] P.C. Duineveld, Bouncing and coalescence of bubble pairs rising at high Reynolds number in pure water or aqueous surfactant solutions, Appl. Sci. Res. 58 (1998) 409-439.

[48] L. Doubliez, The drainage and rupture of a non-foaming liquid film formed upon bubble impact with a free surface, Int. J. Multiph. Flow. 17 (1991) 783-803.

[49] S. Orvalho, M.C. Ruzicka, G. Olivieri, A. Marzocchella, Bubble coalescence: Effect of bubble approach velocity and liquid viscosity, Chem. Eng. Sci. 134 (2015) 205-216.

[50] P.L.L. Walls, L. Henaux, J.C. Bird, Jet drops from bursting bubbles: How gravity and viscosity couple to inhibit droplet production, Phys. Rev. E - Stat. Nonlinear, Soft Matter Phys. 92 (2015) 4-7.

[51] S. Hwang, C. Tsonopoulos, Density , Viscosity , and Surface Tension of Coal Liquids at High Temperatures and Pressures, (1982) 127-134.

[52] E. Ghabache, A. Antkowiak, C. Josserand, T. S On, On the physics of fizziness: How bubble bursting controls droplets ejection, Phys. Fluids. 26 (2014).

[53] J. Piskorz, A. Vladars-Usas, D. Radlein, P. Majerski, D.. Scott, Flash pyrolysis of cellulose for production of anhydro-oligomers, J. Anal. Appl. Pyrolysis. 56 (2000) 145-166.

[54] L. Ghazaryan, Aerosol dynamics in porous media, $\mathrm{PhD}$ dissertation. University of Twentee, 2000.

[55] Y. Wang, S. Wang, F. Leng, J. Chen, L. Zhu, Z. Luo, Separation and characterization of pyrolytic lignins from the heavy fraction of bio-oil by molecular distillation, Sep. Purif. Technol. 152 (2015) 123-132.

[56] X. Gong, Y. Yu, X. Gao, Y. Qiao, M. Xu, H. Wu, Formation of anhydro-sugars in the primary volatiles and solid residues from cellulose fast pyrolysis in a wiremesh reactor, Energy and Fuels. 28 (2014) 5204-5211. 


\section{List of Figure:}

Figure 1. Dynamic life of a bubble on a liquid surface

Figure 2. Pyroprobe-based fast pyrolysis visualization reactor and temperature calibration

Figure 3. Sequence of photographs with major changes during devolatilization of sucrose and Organosolv lignin (Disc Temperature - Sample Temperature)

Figure 4. Birth of bubbles in the intermediate stage of lignin pyrolysis

Figure 5. Sequence of frames to describe the birth of bubbles in the liquid phase intermediate formed during the fast pyrolysis of Sucrose

Figure 6. Monitoring the growth of a gas bubble in the molten sucrose and lignin

Figure 7. Change in the distribution function of the bubbles to the molten phase of Organosolv lignin

Figure 8. Change in the distribution function of the bubbles to the molten phase of sucrose

Figure 9. Representation of the distribution functions of the net rate of birth and death of bubbles during devolatilization of Organosolv lignin and Sucrose

Figure 10. Sequence of formation and collapse of bubbles in liquid-gas interface during the fast pyrolysis of organosolv lignin

Figure 11. Sequence formation, breaking bubbles (Bursting) and release of jets, during the fast pyrolysis of sucrose

Figure 12. Bubble bursting rates for individual bubbles and the sum of bursting rates for Organosolv lignin and sucrose

Figure 13. Distribution aerosol function of time and droplet diameter 


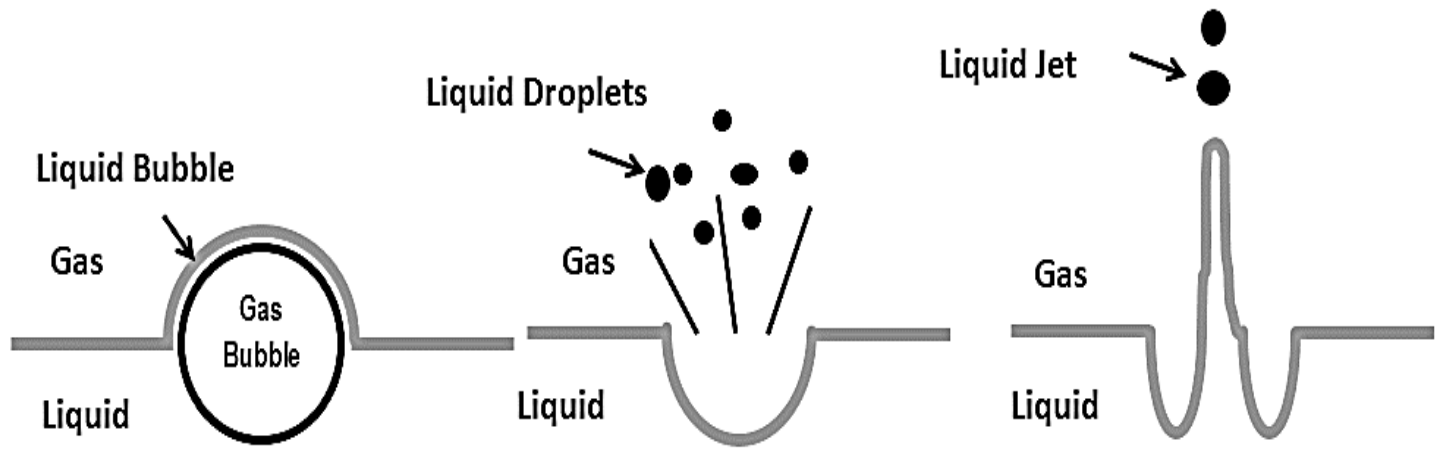

Figure 1. Dynamic life of a bubble on a liquid surface [9] 


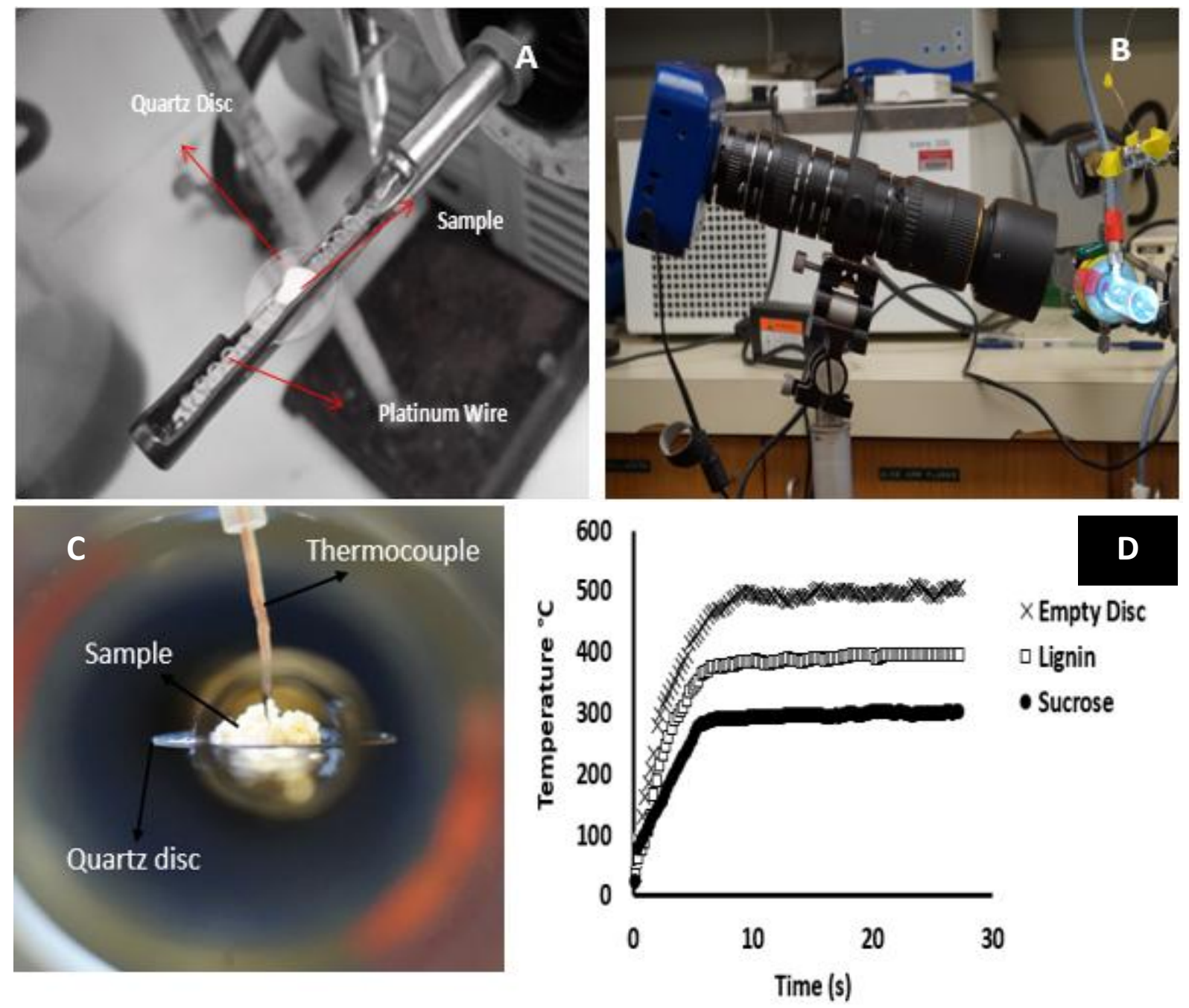

Figure 2. Pyroprobe-based fast pyrolysis visualization reactor and temperature calibration. A: Modified heating element and quartz sample disc with a cellulose sample. B: A view of the setup used for visualization, where the reactor on the right is lit up by a fiber-optic light source. Nitrogen purges through the reactor, which is open on the end, and a thermocouple can be fed through a tiny hole in the glass tube to measure temperature on the sample or quartz disc C: Positioning the thermocouple and sample calibration curve. D: Final temperatures on the lignin $\left(\sim 400{ }^{\circ} \mathrm{C}\right)$ and sucrose $\left(\sim 280{ }^{\circ} \mathrm{C}\right)$ are due to the fact that the thermocouple is not touching the quartz. Because char has a low thermal conductivity, heat is not transferred well through the char, which has room-temperature nitrogen flowing over the top 


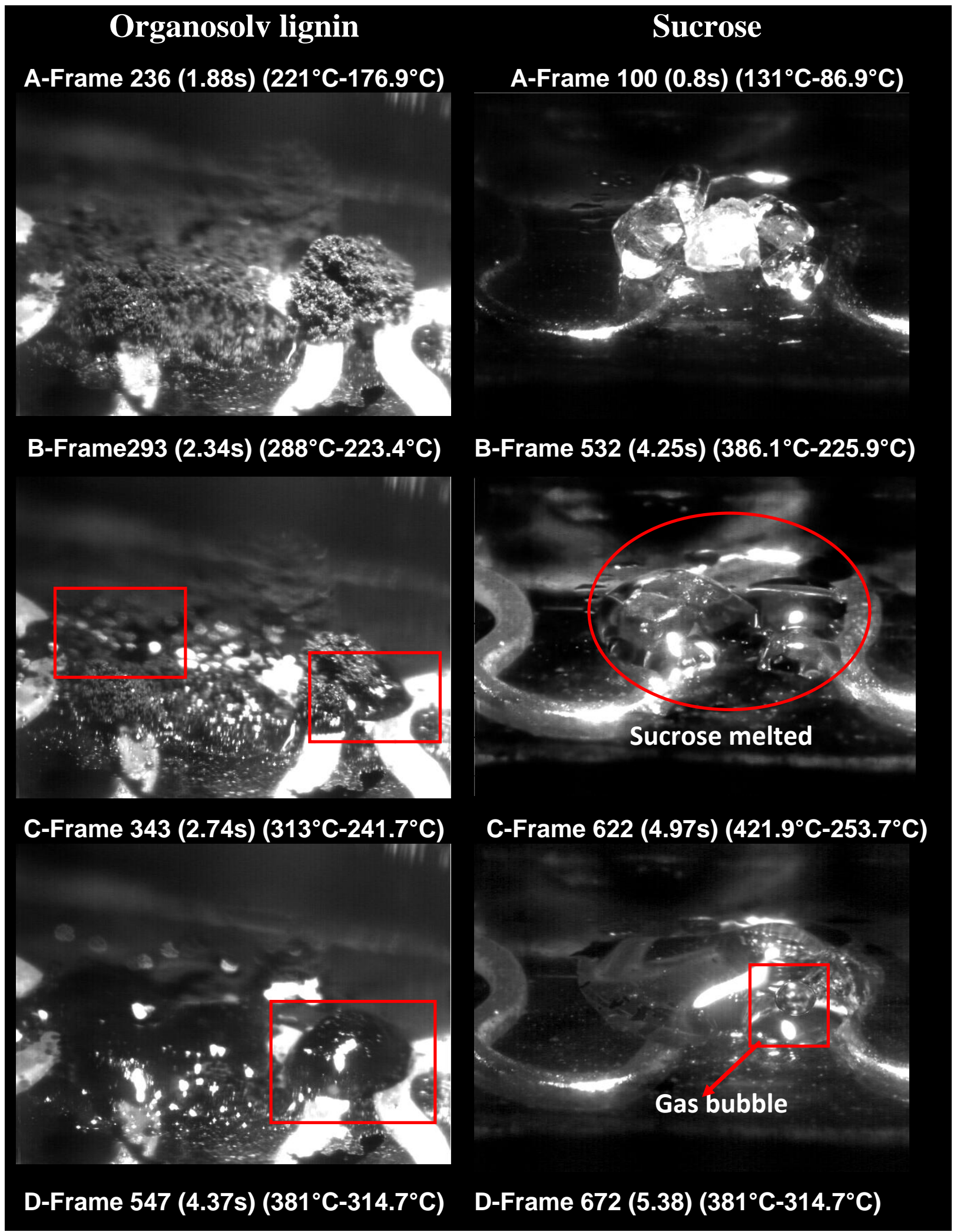




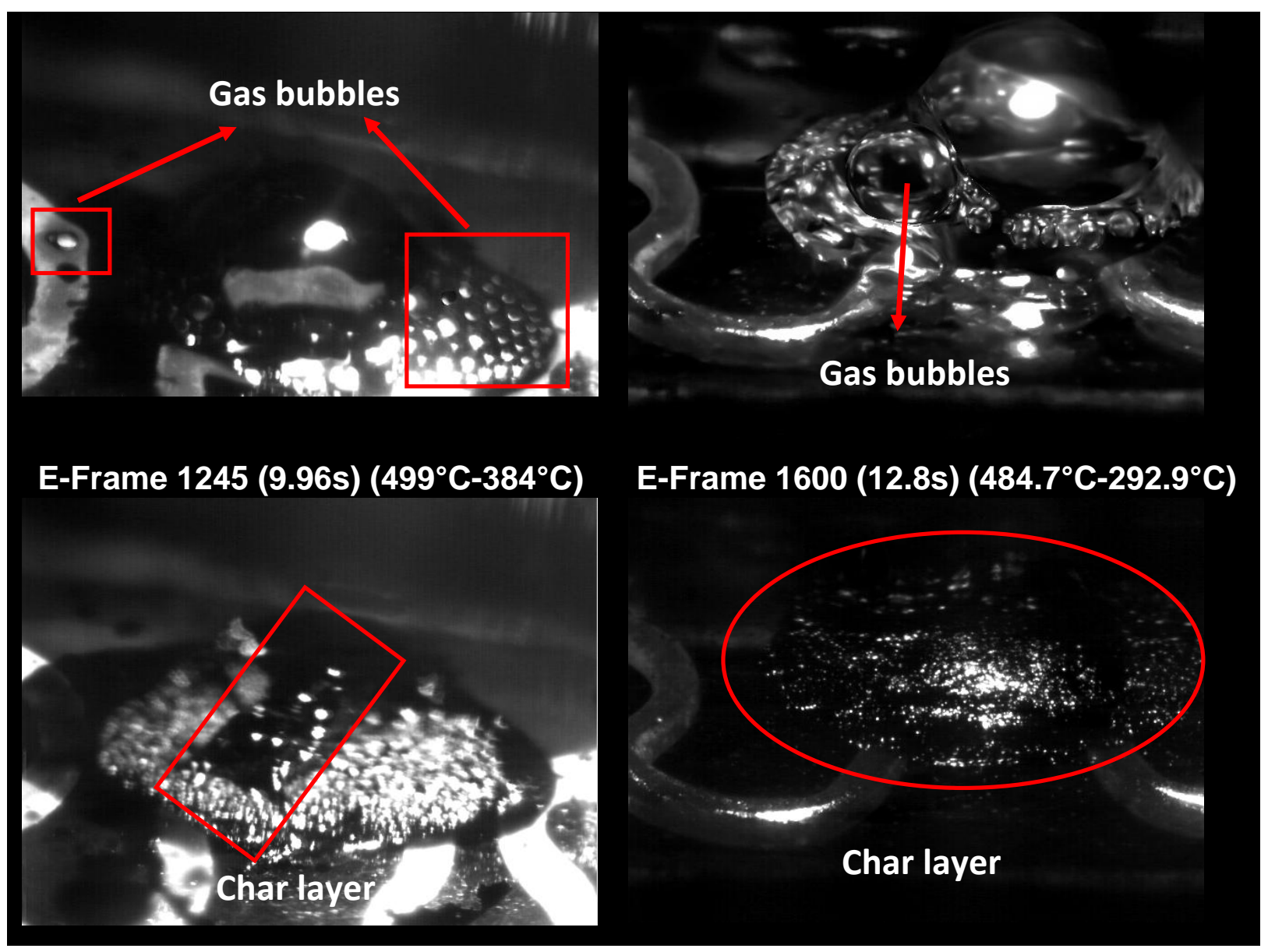

Figure 3. Sequence of photographs with major changes during devolatilization of sucrose and Organosolv lignin (Disc Temperature - Sample Temperature) 


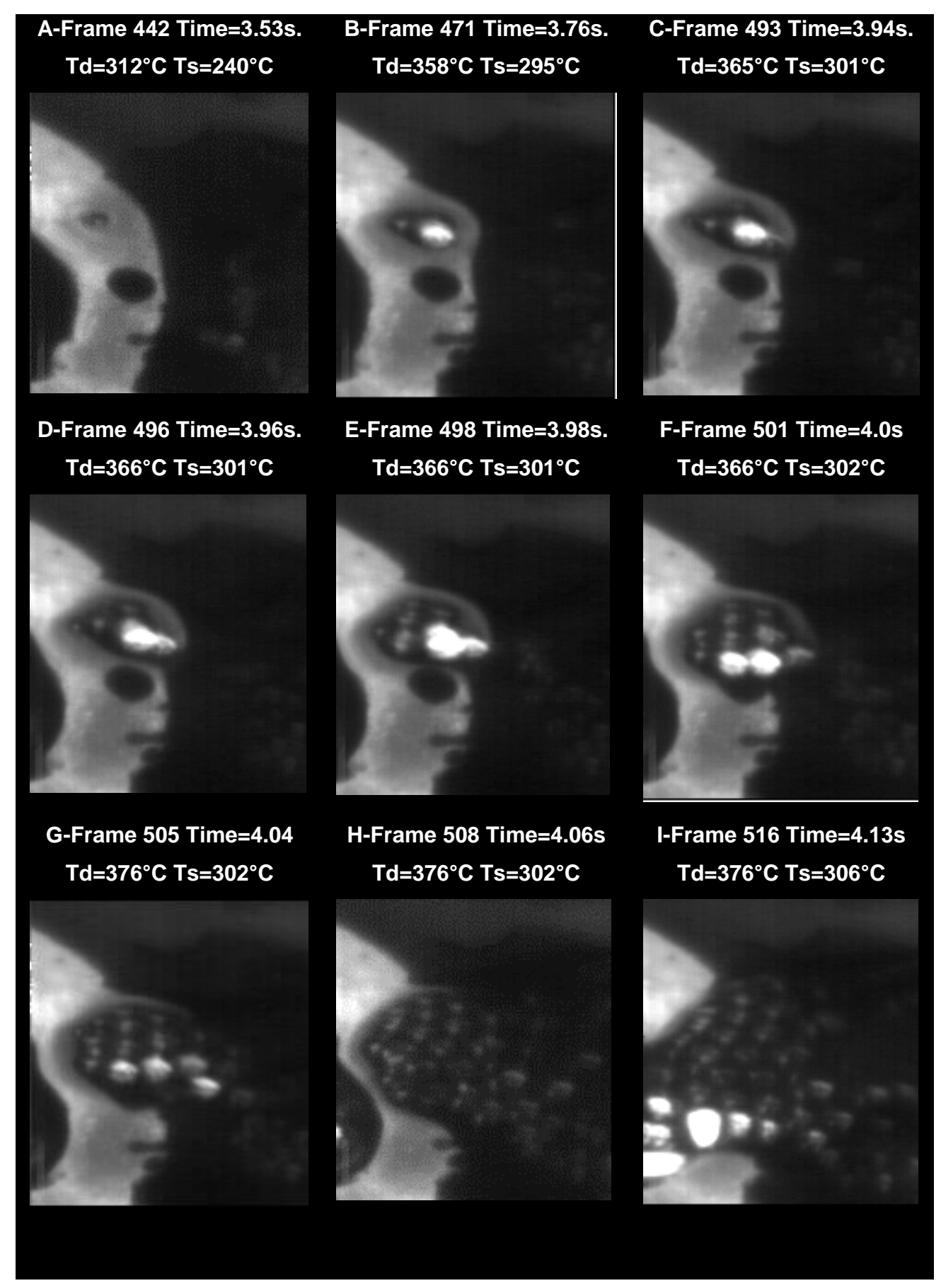

Figure 4. Birth of bubbles in the intermediate stage of lignin pyrolysis 


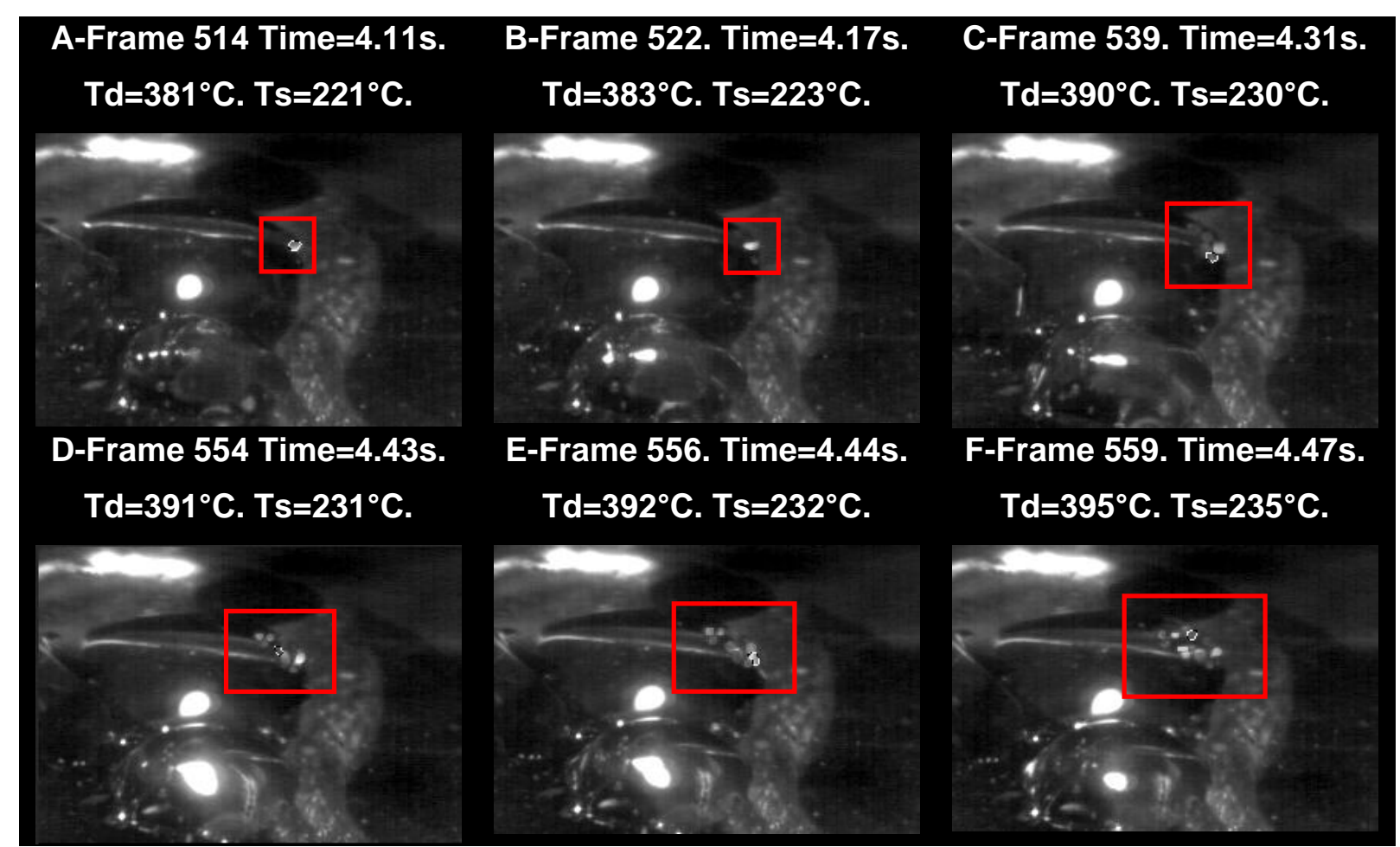

Figure 5. Sequence of frames to describe the birth of bubbles in the liquid phase intermediate formed during the fast pyrolysis of Sucrose 


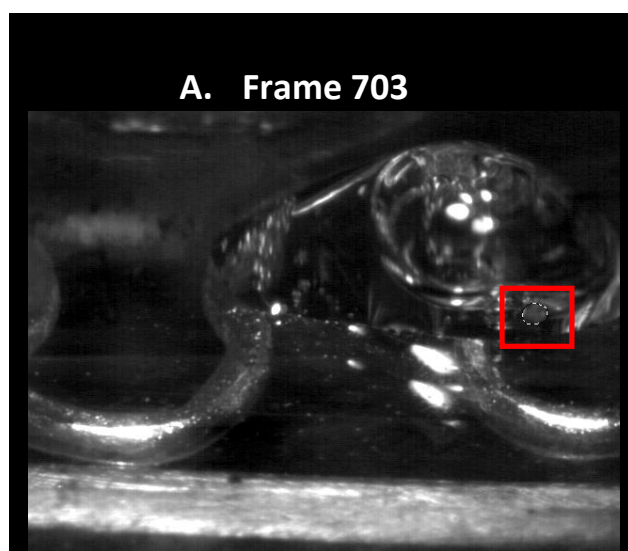

D. Frame $\mathbf{7 1 0}$
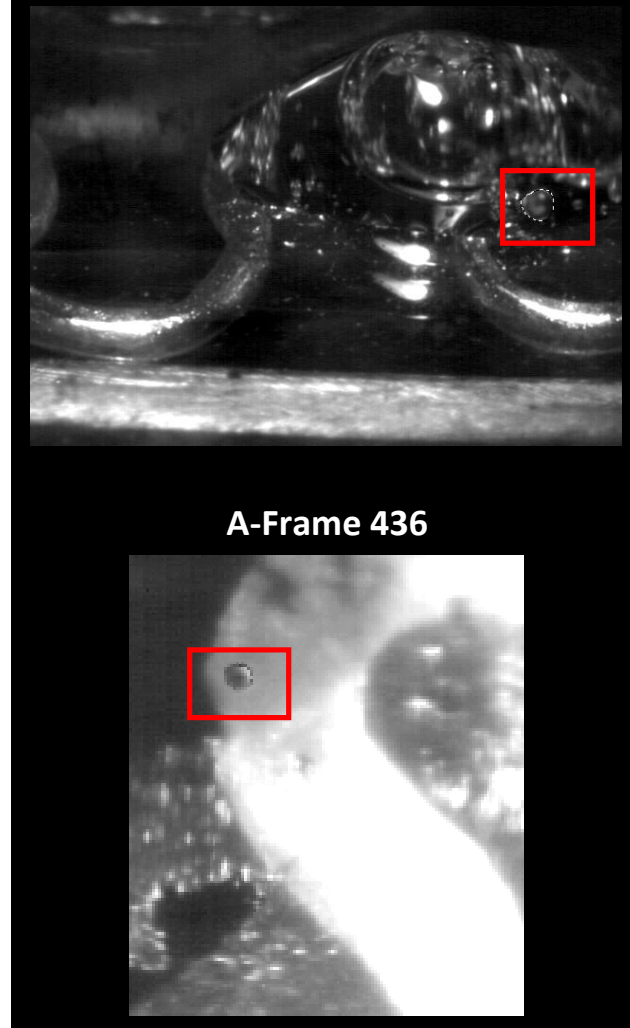

\section{D-Frame 442}

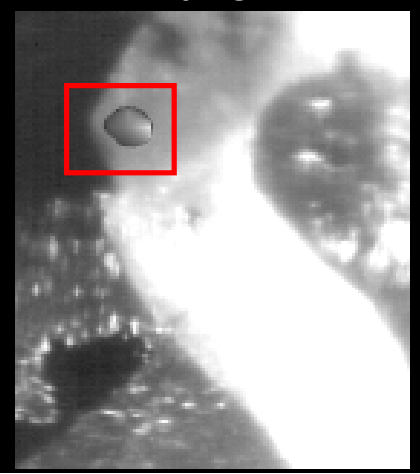

\section{Sucrose}

B. Frame $\mathbf{7 0 5}$

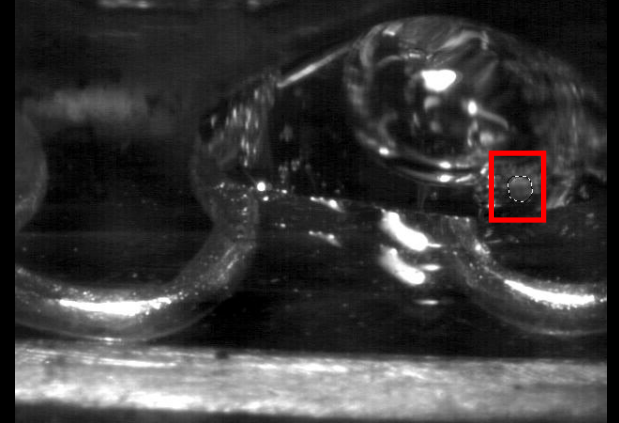

E. Frame $\mathbf{7 1 2}$

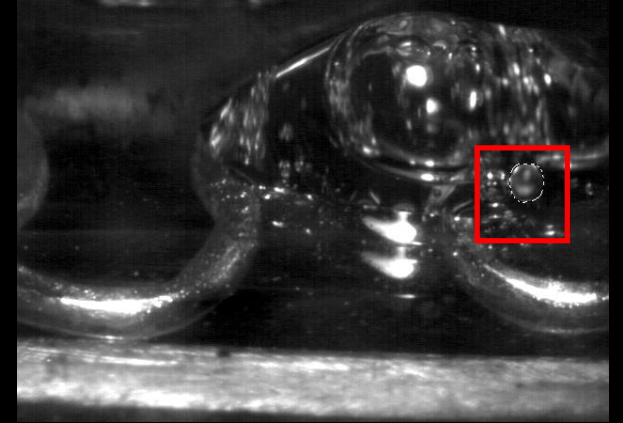

Organosolv lignin

B-Frame 438

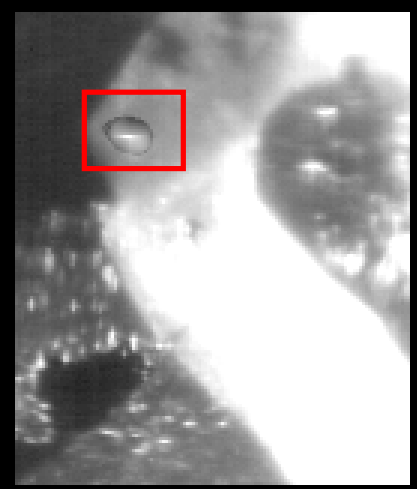

E-Frame 445

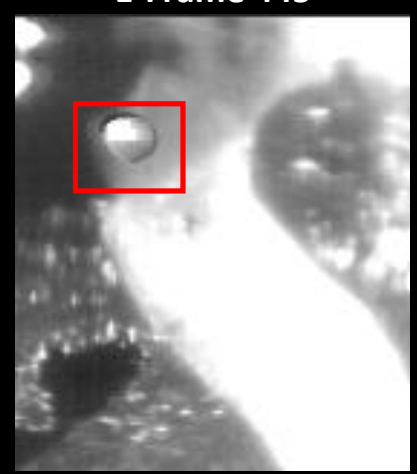

C. Frame $\mathbf{7 0 8}$

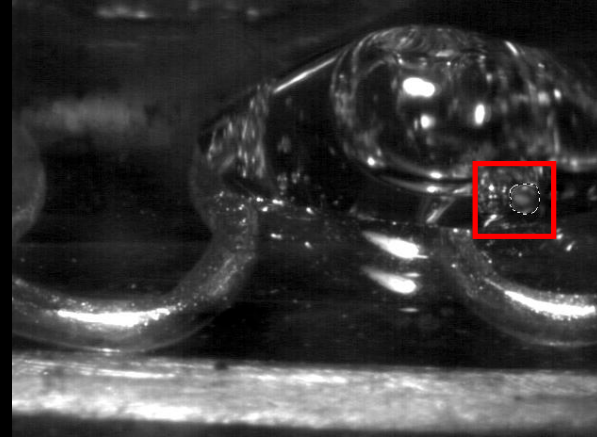

F. Frame $\mathbf{7 1 5}$

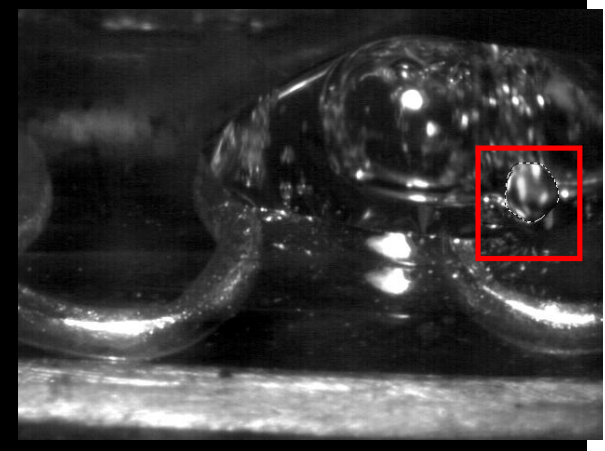

\section{C-Frame 440}

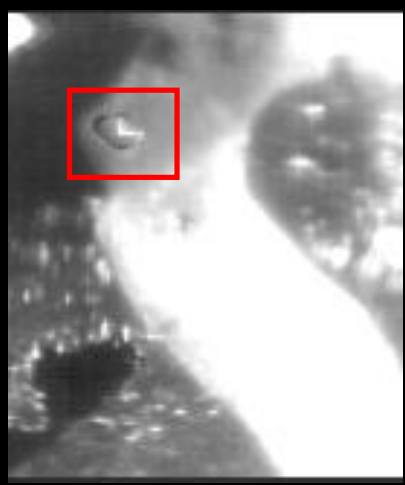

F-Frame 447

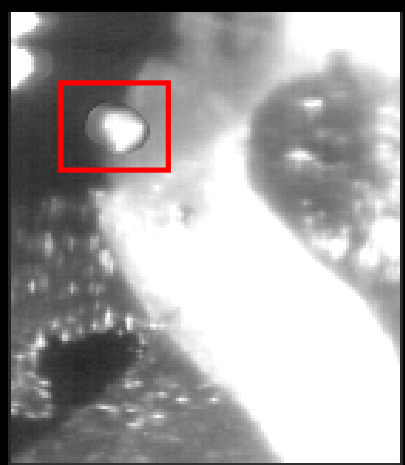

Figure 6. Monitoring the growth of a gas bubble in the molten sucrose and organosolv lignin 

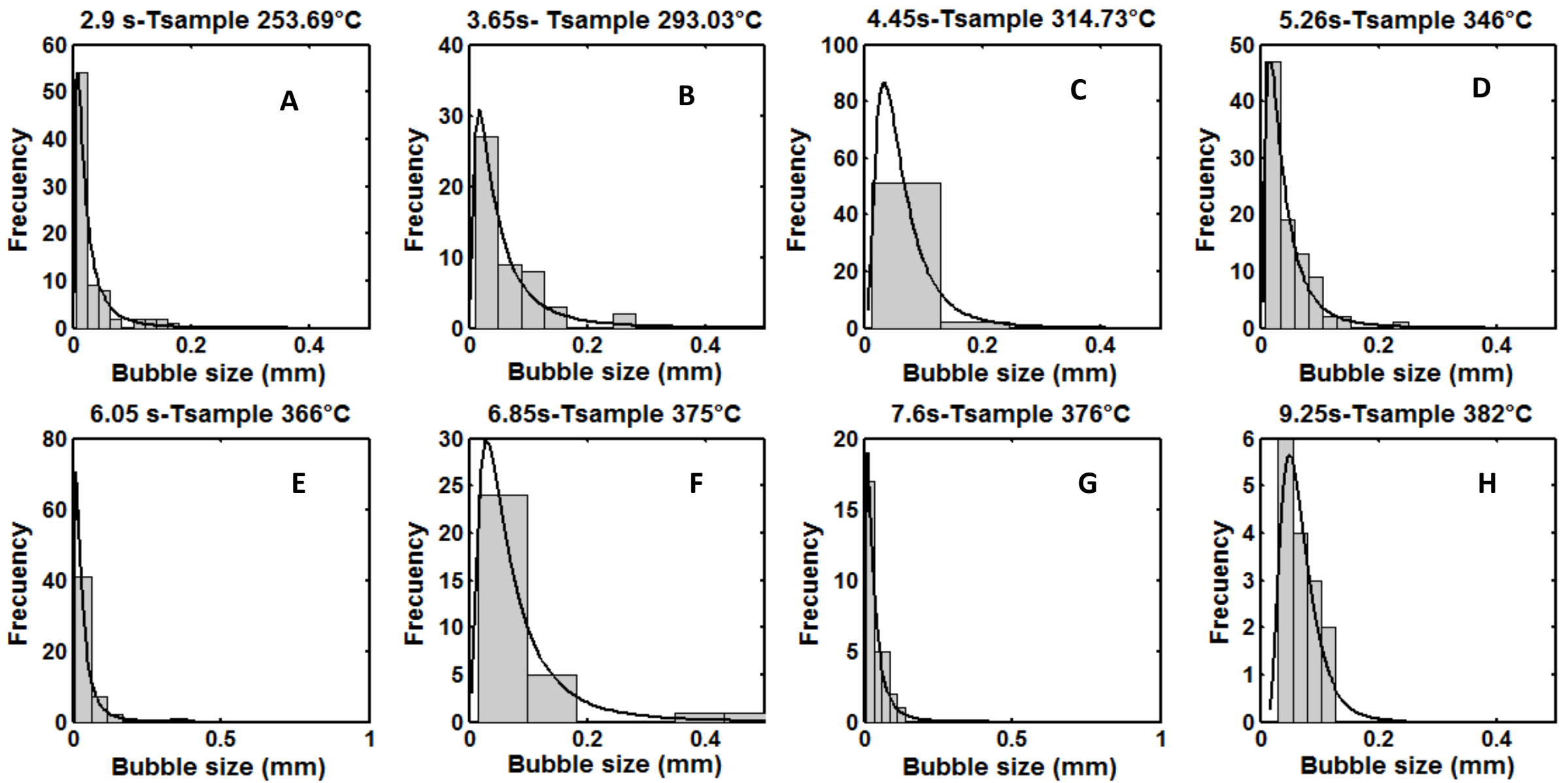

Figure 7. Change in the distribution function of the bubbles to the molten phase of Organosolv lignin 

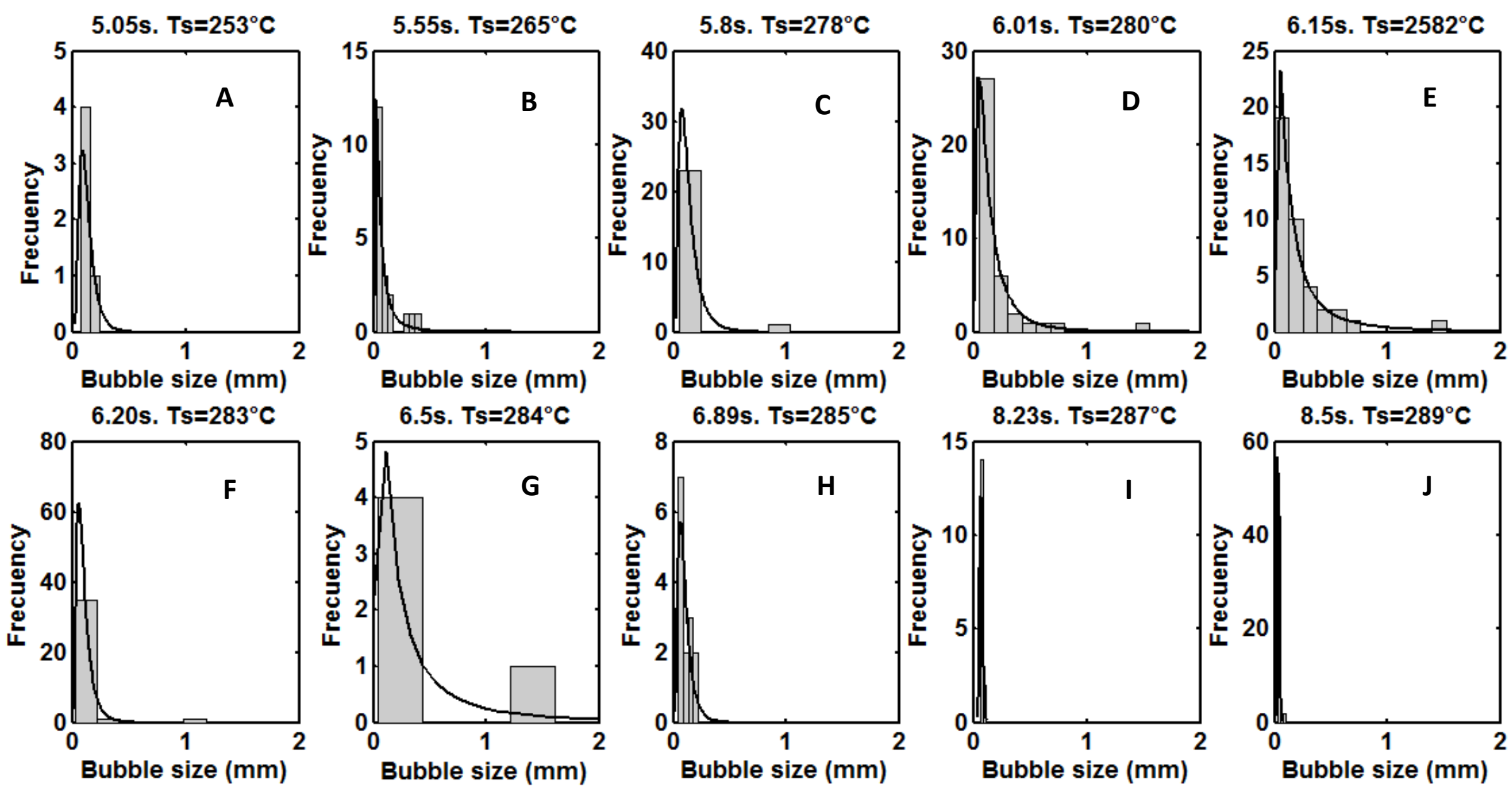

Figure 8. Change in the distribution function of the bubbles to the molten phase of sucrose 

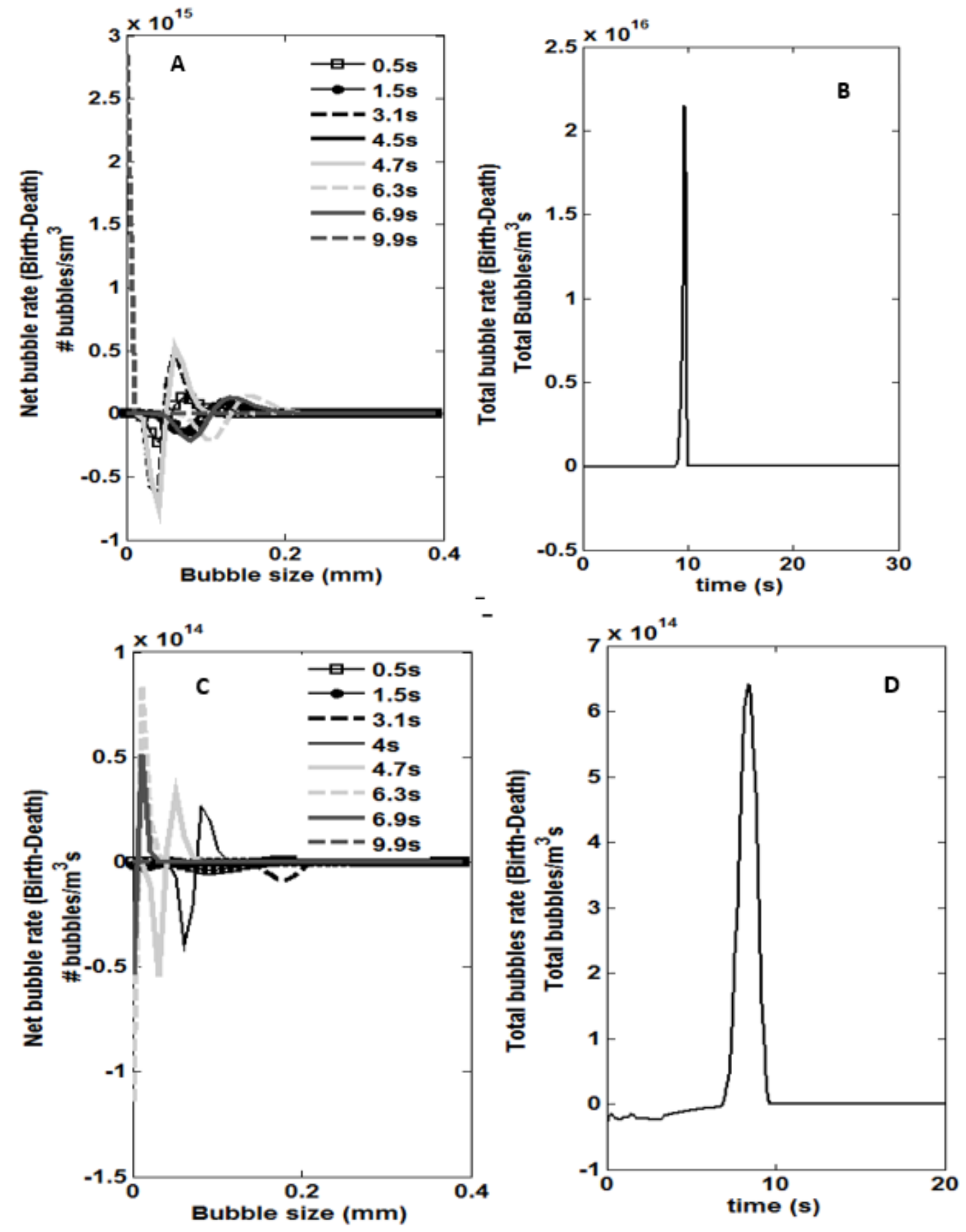

Figure 9. Representation of the distribution functions of the net rate of birth and death of bubbles during devolatilization of Organosolv lignin and Sucrose. A:. Net rate of birth and death of bubbles within the liquid phase of the Organosolv lignin. B. Total net rate of birth and death of bubbles within the liquid phase of the Organosolv lignin. C. Net rate of birth and death of bubbles within the liquid phase of sucrose. D. Total net rate of birth and death of bubbles within the liquid phase of sucrose 


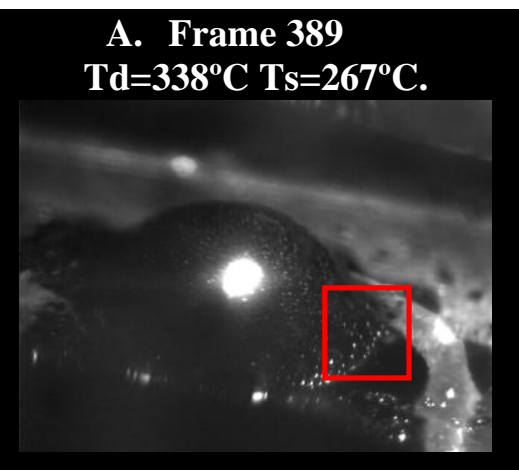

F. Frame 408

$\mathrm{Td}=342^{\circ} \mathrm{C}$ Ts $=274^{\circ} \mathrm{C}$.

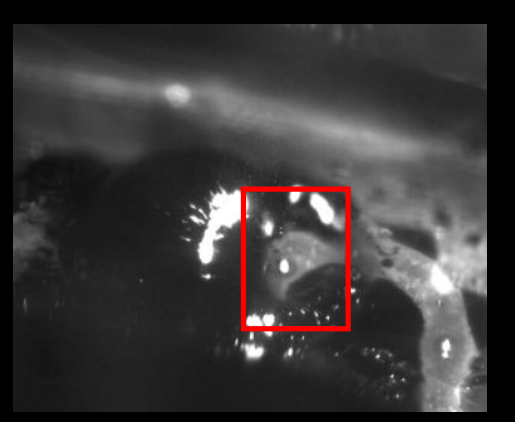

K. Frame 494

$\mathrm{Td}=376^{\circ} \mathrm{C}$ Ts $=301^{\circ} \mathrm{C}$.

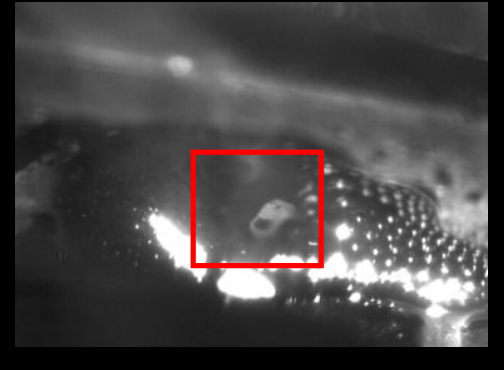

B. Frame 394

$\mathrm{Td}=340^{\circ} \mathrm{C} \mathrm{Ts}=270^{\circ} \mathrm{C}$.

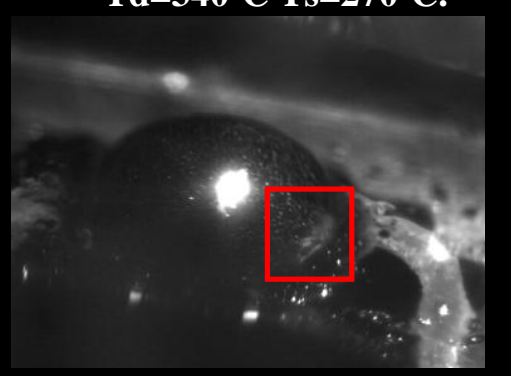

G. Frame 409

$\mathrm{Td}=342^{\circ} \mathrm{C}$ Ts $=274^{\circ} \mathrm{C}$.

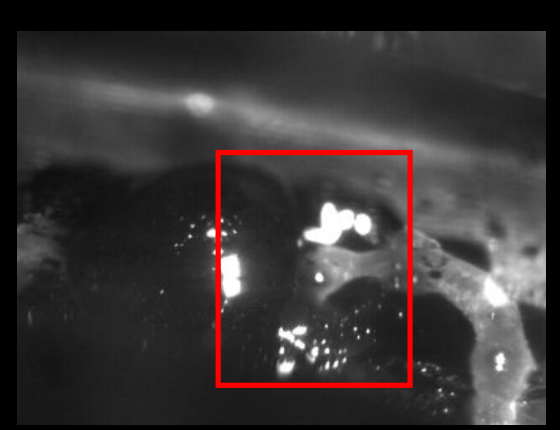

L. Frame 496 $\mathrm{Td}=376^{\circ} \mathrm{C} \mathrm{Ts}=301^{\circ} \mathrm{C}$.

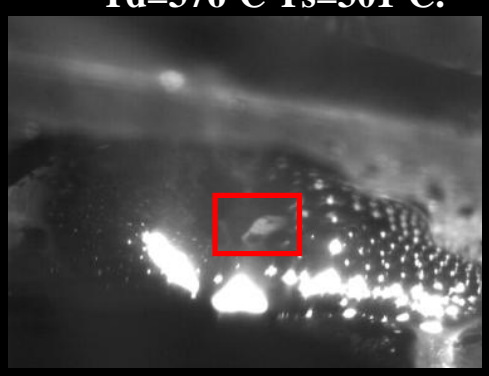

C. Frame 398

$\mathrm{Td}=340^{\circ} \mathrm{C} \mathrm{Ts}=270^{\circ} \mathrm{C}$.

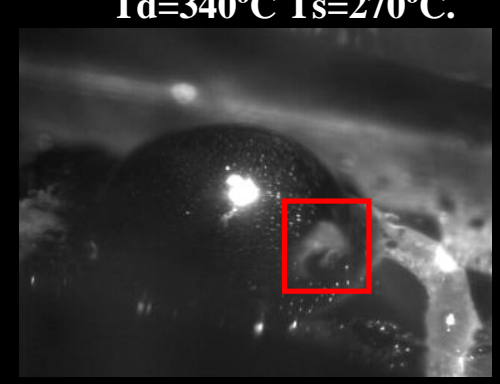

H. Frame 411

$\mathrm{Td}=343^{\circ} \mathrm{C} \mathrm{Ts}_{\mathrm{s}}=275^{\circ} \mathrm{C}$.

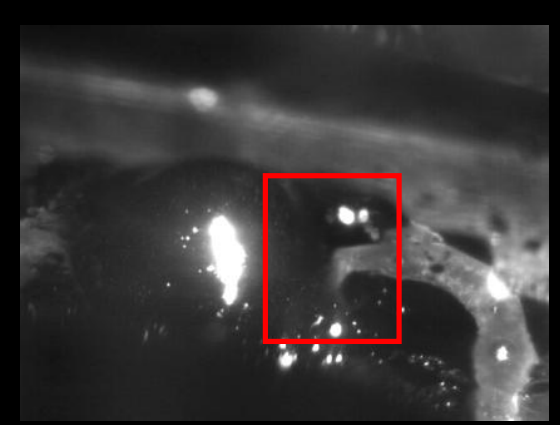

M. Frame 498

$\mathrm{Td}=377^{\circ} \mathrm{C} \mathrm{Ts}=301^{\circ} \mathrm{C}$.

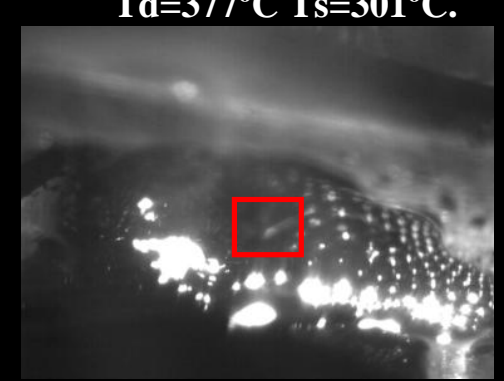

D. Frame 404

$\mathrm{Td}=342^{\circ} \mathrm{C}$ Ts $=274^{\circ} \mathrm{C}$.

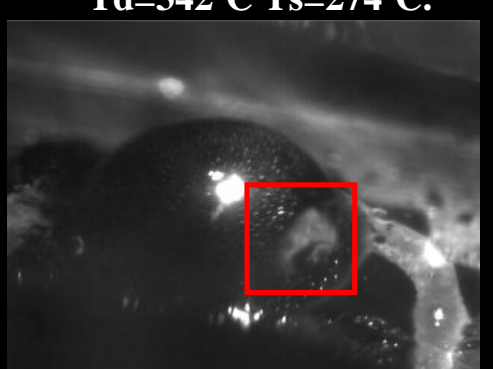

I. Frame 492

$\mathrm{Td}=375^{\circ} \mathrm{C}$ Ts $=300^{\circ} \mathrm{C}$.

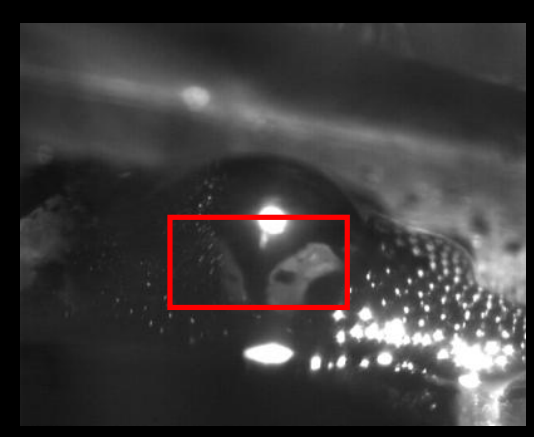

N. Frame 501

$\mathrm{Td}=377^{\circ} \mathrm{C}$ Ts $=302^{\circ} \mathrm{C}$.

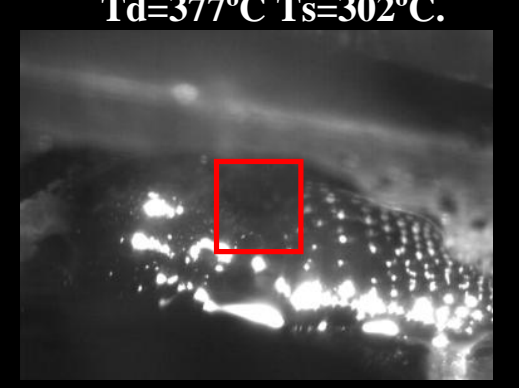

E. Frame 407

$\mathrm{Td}=342^{\circ} \mathrm{C}$ Ts $=274^{\circ} \mathrm{C}$.

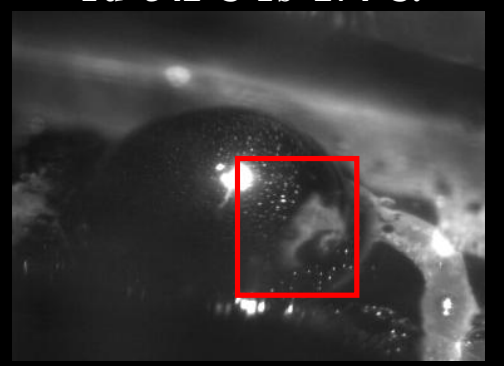

J. Frame 493

$\mathrm{Td}=375^{\circ} \mathrm{C} \mathrm{Ts}=300^{\circ} \mathrm{C}$

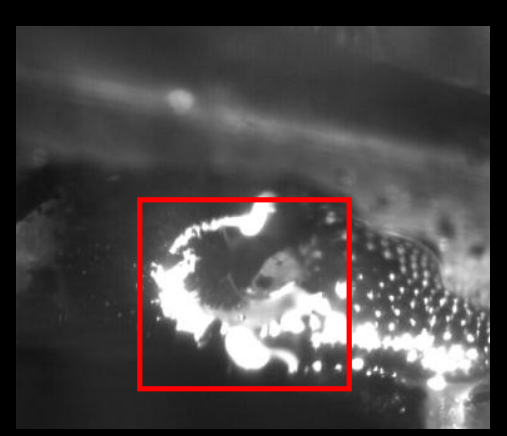

O. Frame 527

$\mathrm{Td}=388^{\circ} \mathrm{C}$ Ts $=312^{\circ} \mathrm{C}$.

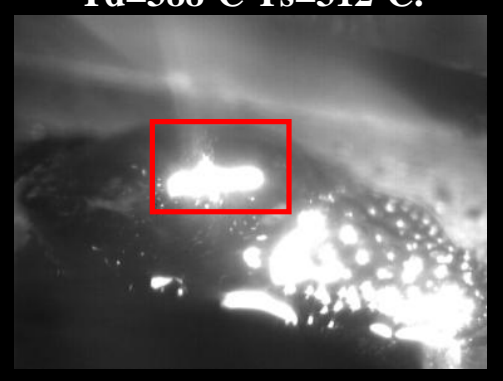

Figure 10. Sequence of formation and collapse of bubbles in liquid-gas interface during the fast pyrolysis of organosolv lignin 


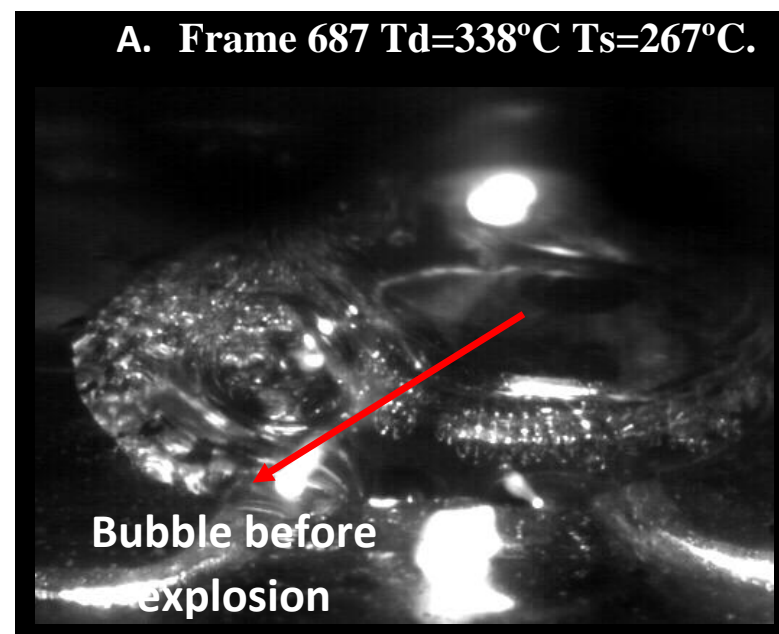

C. Frame $689 \mathrm{Td}=338^{\circ} \mathrm{C} \mathrm{Ts}=267^{\circ} \mathrm{C}$.
B. Frame $688 \mathrm{Td}=340^{\circ} \mathrm{C} \mathrm{Ts}=270^{\circ} \mathrm{C}$.

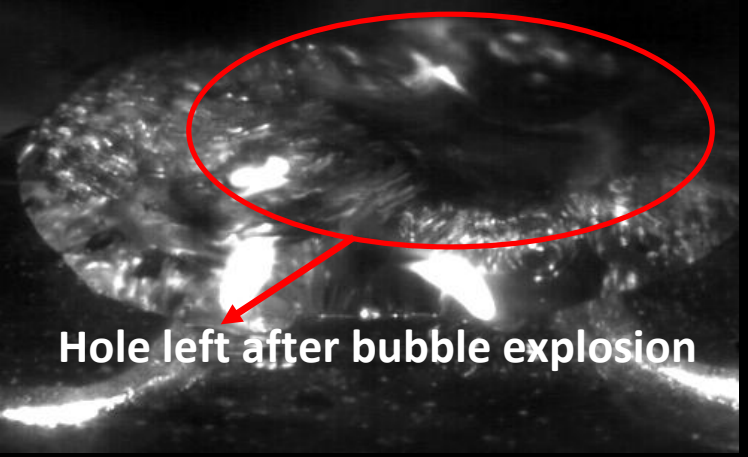

D. Frame $690 \mathrm{Td}=340^{\circ} \mathrm{C} \mathrm{Ts}=270^{\circ} \mathrm{C}$.

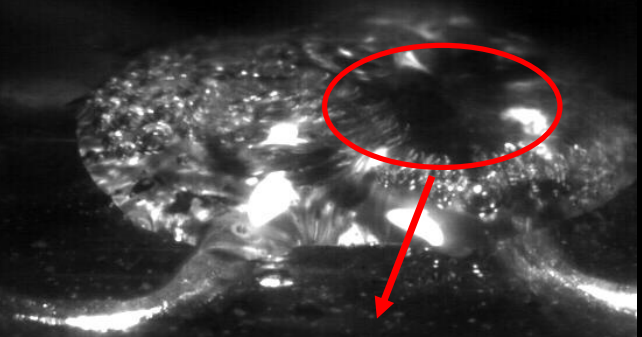

Hole contraction

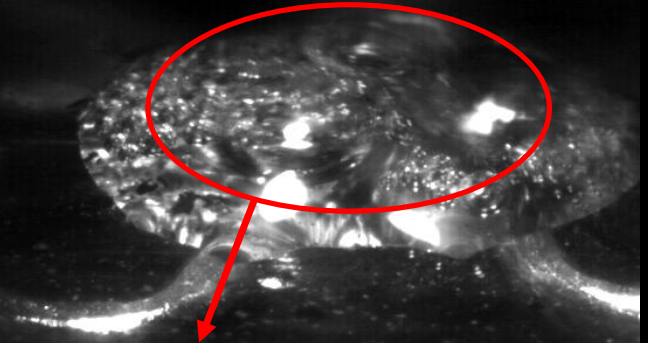

Hole filled

E. Frame $766 \mathrm{Td}=338^{\circ} \mathrm{C} \mathrm{Ts}=267^{\circ} \mathrm{C}$.

F. Frame $768 \mathrm{Td}=340^{\circ} \mathrm{C} \mathrm{Ts}=270^{\circ} \mathrm{C}$.

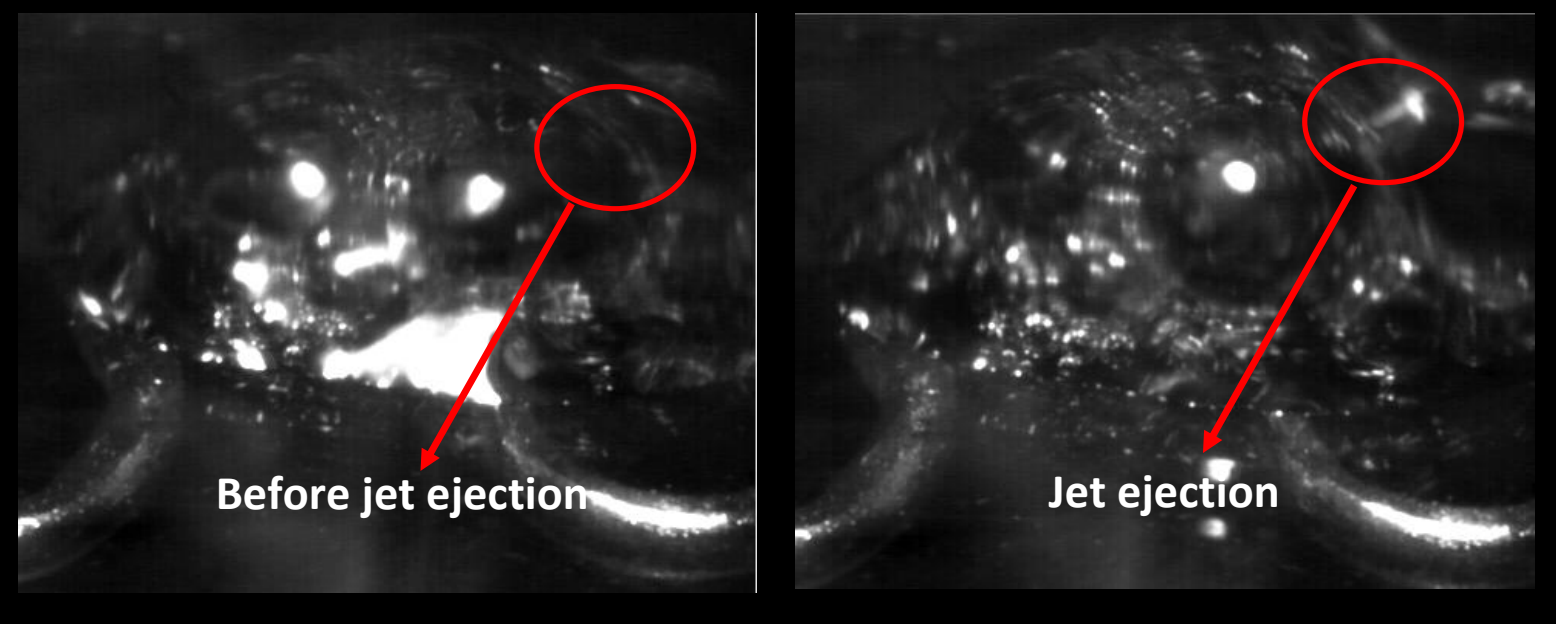

Figure 11. Sequence formation, breaking bubbles (Bursting) and release of jets, during the fast pyrolysis of sucrose 

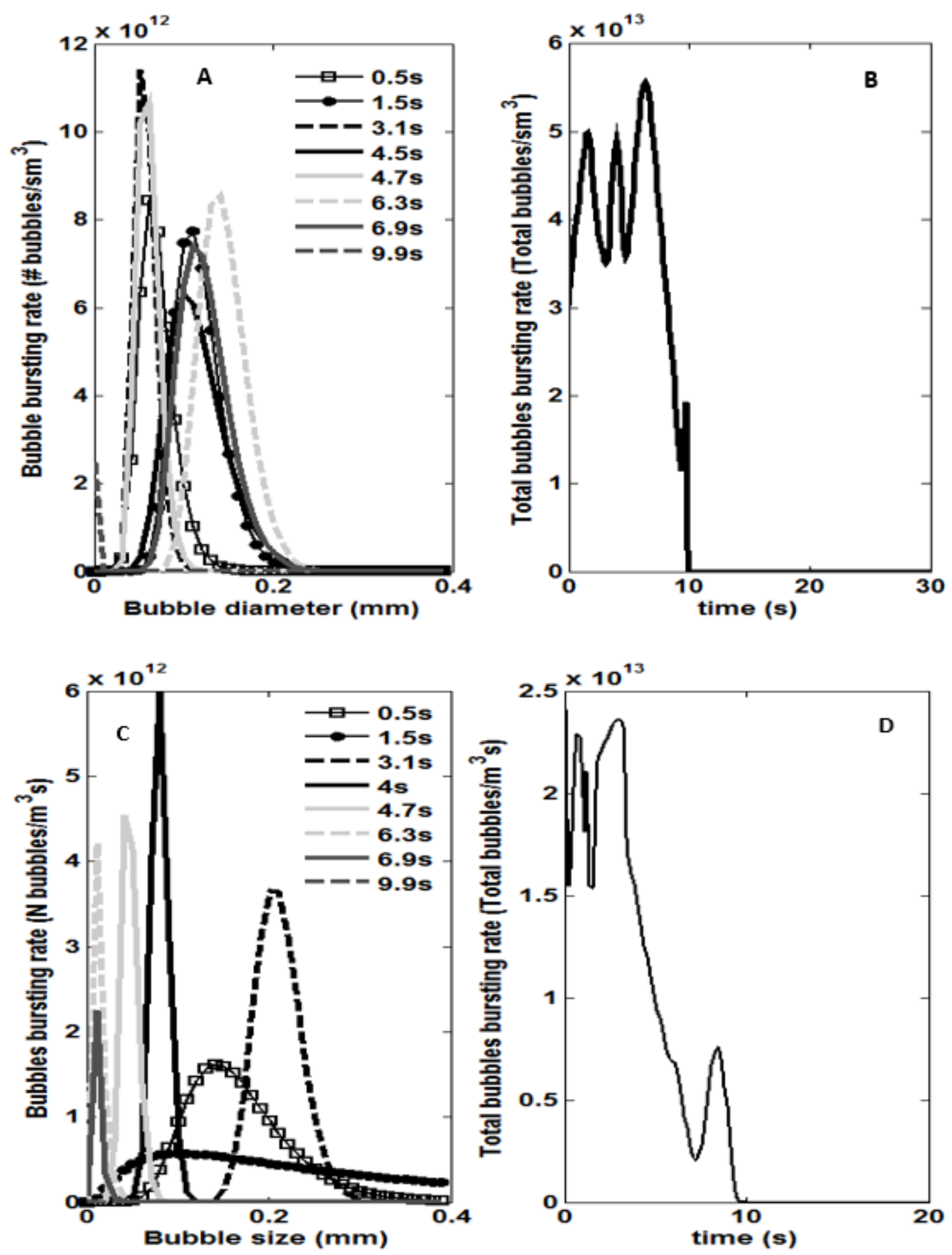

Figure 12. Bubble bursting rates for individual bubbles and the sum of bursting rates for Organosolv lignin and sucrose. A. Bubble bursting rates for Organosolv lignin pyrolysis. B. Total Bubble bursting rate for Organosolv lignin pyrolysis. C. Bubble bursting rates for sucrose pyrolysis. D. Total bubble bursting rate for sucrose pyrolysis 

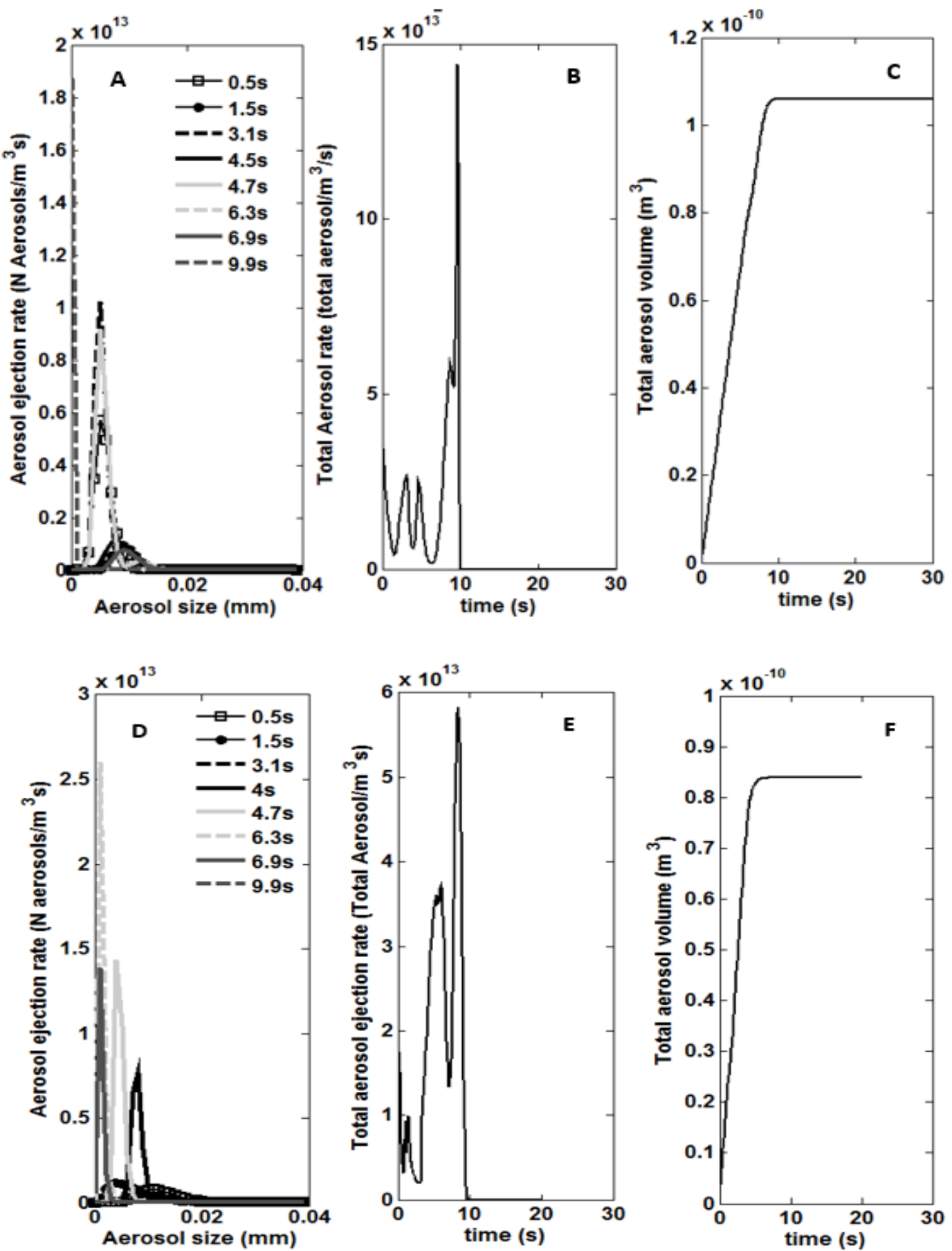

Figure 13. Distribution aerosol function of time and droplet diameter 